\title{
Low-Dimensional Materials and State-of-the-Art Architectures for Infrared Photodetection
}

\author{
Nasir Ilyas ${ }^{1}$, Dongyang $\mathrm{Li}^{1}$, Yuhao Song ${ }^{1}$, Hao Zhong ${ }^{1}$, Yadong Jiang ${ }^{2}$ and Wei $\mathrm{Li}^{2, *}$ \\ 1 School of Optoelectronic Information, University of Electronic Science and Technology of China, Chengdu \\ 610054,China; ilyas_nasir84@yahoo.com (N.I.); open_please@163.com (D.L.); 15528122306@163.com (Y.S.); \\ zhonghao729@foxmail.com (H.Z.) \\ 2 State Key Laboratory of Electronic Thin Films and Integrated Devices, University of Electronic Science and \\ Technology of China, Chengdu 610054, China; jiangyd@uestc.edu.cn \\ * Correspondence: wli@uestc.edu.cn; Tel.: +86-138-0801-8859
}

Received: 29 October 2018; Accepted: 22 November 2018; Published: 27 November 2018

check for updates

\begin{abstract}
Infrared photodetectors are gaining remarkable interest due to their widespread civil and military applications. Low-dimensional materials such as quantum dots, nanowires, and two-dimensional nanolayers are extensively employed for detecting ultraviolet to infrared lights. Moreover, in conjunction with plasmonic nanostructures and plasmonic waveguides, they exhibit appealing performance for practical applications, including sub-wavelength photon confinement, high response time, and functionalities. In this review, we have discussed recent advances and challenges in the prospective infrared photodetectors fabricated by low-dimensional nanostructured materials. In general, this review systematically summarizes the state-of-the-art device architectures, major developments, and future trends in infrared photodetection.
\end{abstract}

Keywords: infrared photodetectors; plasmonic waveguides; nanostructures

\section{Introduction}

The extensive study of light-matter interaction has unveiled many dark secrets of the universe and has led to many revolutionary scientific discoveries. The interaction of light with semiconductors has particularly enabled us to understand the behavior of various fundamental phenomena and laid the foundation of optoelectronic systems that we rely on today. Most of these systems involve the detection of light, and most of them are commonly found in our routine life such as digital cameras and night vision goggles [1]. The rapid advancement in semiconductor materials in the past few decades have developed photodetectors for various applications such as motion detection, telecommunication, astronomy observation [2], and atmospheric spectroscopy [3]. It involves the detection of light with broad-range wavelengths from 0.75 to $\geq 1000 \mu \mathrm{m}$, covering the spectrum of near-IR (NIR), short-wavelength IR (SWIR), mid-wavelength IR (SWIR), long- wavelength IR (LWIR), and far-IR (FIR). Figure 1 shows some typical applications of IR-photodetectors from NIR to FIR spectra.

Over the last few years, research and development efforts at the nanoscale interaction of light with materials have enabled researchers to develop highly efficient photodetectors responsive to a particular region of the electromagnetic (EM) spectrum [4-7]. The reduced geometry impacts the response time up to $\sim$ picosecond, which leads to facilitation of the fabrication of high-performance photodetectors for optical communication and high frame cameras [8,9]. In last few years, lead sulfide $(\mathrm{PbS})$ nanocrystal has emerged as one of the most relatively substantive materials for infrared photodetectors (IRPDs). The PbS-based photodetectors are advantageous in various aspects, including low-cost manufacturing, wideband sensitivity, and flexible substrate compatibility [4]. Photodetectors 
assembled with $\mathrm{PbS}$ quantum dots and 2D graphene have reached an ultra-high detectivity over $7 \times 10^{13}$ Jones, with exceptionally high photo gain $\left(\geq 10^{8}\right) @$ MWIR band [10].

\begin{tabular}{|c|c|c|c|c|}
\hline 0.76 & & & & $100+(\mu \mathrm{m}$ \\
\hline NIR & SWIR & MWIR & LWIR & $\mathrm{FIR} / \mathrm{THz}$ \\
\hline \multicolumn{5}{|c|}{ Applications } \\
\hline Bio-Imaging & $\begin{array}{l}\text { Telecommunica } \\
\text { tion }\end{array}$ & $\begin{array}{l}\text { Chemical } \\
\text { analysis }\end{array}$ & $\begin{array}{l}\text { Thermal } \\
\text { Imaging }\end{array}$ & $\begin{array}{l}\text { Medical } \\
\text { Imaging }\end{array}$ \\
\hline
\end{tabular}

Figure 1. The typical photodetector applications at broad infrared detection spectral bands, including NIR, SWIR, MWIR, LWIR and FIR/THz.

The $\mathrm{p}-\mathrm{n}$ or Schottky junction is a building block of the various modern semiconductor devices. By developing $\mathrm{p}-\mathrm{n}$ or the Schottky junction in nanowire, including different hybrid heterostructure-based infrared photodetectors, a low-leakage current has been achieved [11-15]. Moreover, researchers have successfully suppressed dark current and shown prospective in constructing room temperature infrared photodetectors (IRPDs) with enhanced optoelectronic properties. The low-dimensional nanostructured materials have added some additional functionalities such as color- and polarization-sensitive detection in existing photodetector devices [16-20]. Furthermore, the manipulation of light with nanostructured materials beyond the diffraction limit significantly enhances at the sub-wavelength level [21-25]. In nanostructured materials, several achievements from different aspects such as detectivity, response speed, and operational temperature have been pointed out for high-performance IRPDs.

A material dubbed black silicon (BS) has shown great promise for making cheaper, more sensitive light detectors and imaging devices. Due to its nanostructured surface and narrow band gap, it is feasible to achieve high absorptance ( $>90 \%$ ) over a broad spectrum from $250 \mathrm{~nm}$ to $2500 \mathrm{~nm}$ [26]. Additionally, the high photoconductive gain and responsivity (0.57 A/W at $1050 \mathrm{~nm}$ wavelength) [27] gives rise to the practical device applications for IR detection.

Despite traditional low-dimensional materials, exploring novel materials with rapidly controlled size and advanced architectures are crucial to improving the performance and functionalities of the existing devices. Therefore, this article discusses the recent developments and trends in state-of-the-art IRPDs based on novel low-dimensional nanostructured materials such as quantum wells (QWs), quantum dots (QDs), nanowires (NWs), and 2D materials including graphene and black phosphorus. Moreover, some hybrid combinations of different low-dimensional materials and integration of plasmonic nanostructures for the confinement of light beyond the diffraction limits are also discussed. Furthermore, we will summarize the possible challenges and prospects of these photodetectors.

\section{Nanostructured IR Sensitive Materials for Photodetectors}

Nanostructured IR sensitive materials have gained significant interests in photodetection technology. The enhancement of photosensitivity becomes possible by tailoring the materials' properties and their geometry. In this section, we will discuss the current advancements in IRPDs based on different nanostructured materials and the related architectures such as quantum wells (QWs), quantum dots (QDs), nanowires (NWs), and 2D layers and their hybrid heterostructures (HSs). Table 1 gives the IRPDs based on various nanostructured materials with their primary performance parameter. 
Table 1. The list of nanostructured materials and their performance parameters for IR detectors.

\begin{tabular}{|c|c|c|c|c|c|c|c|}
\hline Category & Materials & $\begin{array}{l}\text { Wavelength } \\
\quad(\mu \mathrm{m})\end{array}$ & $\begin{array}{l}\text { Responsivity } \\
{\left[\mathrm{AW}^{-1}\right]}\end{array}$ & $\begin{array}{l}\text { Detectivity } \\
\text { [Jones] }\end{array}$ & $\begin{array}{l}\text { Speed } \\
{[\mathrm{Hz}, \mathrm{s}]}\end{array}$ & $\begin{array}{l}\text { Pub. } \\
\text { Year }\end{array}$ & Ref. \\
\hline \multirow{4}{*}{$\begin{array}{l}\text { Epitaxially } \\
\text { Grown QDs }\end{array}$} & InGaAs/GaAs/AlGaAs & 17 & 0.15 & $1.0 \times 10^{7}$ & - & 2007 & [28] \\
\hline & $\mathrm{GaSb} / \mathrm{AlSb}$ & 3.0 & - & $1.8 \times 10^{11}$ & - & 2013 & [29] \\
\hline & GaAs/AlGaAs & 8.0 & 0.044 & $4.5 \times 10^{11}$ & - & 2005 & [30] \\
\hline & InGaAs/GaAs & 10.2 & 2.16 & $1.0 \times 10^{11}$ & - & 2011 & [31] \\
\hline $\begin{array}{l}\text { Quantum } \\
\text { wells }\end{array}$ & InGaAs/InP & 8.0 & 7.0 & $7.4 \times 10^{10}$ & - & 2010 & [22] \\
\hline \multirow{4}{*}{ Colloidal QDs } & HgTe QDs & $2-65$ & - & - & - & 2018 & [32] \\
\hline & HgTe QDs & 2.0 & - & $2 \times 10^{10}$ & $2 \mathrm{KHz}$ & 2017 & [33] \\
\hline & HgSe QDs & $4.2-9$ & 0.145 & - & - & 2017 & [34] \\
\hline & PbS QDs & 1.3 & $1.0 \times 10^{3}$ & $1.8 \times 10^{13}$ & $18 \mathrm{~Hz}$ & 2006 & [35] \\
\hline \multirow{3}{*}{ Nanowires } & $\operatorname{InP}$ & 0.83 & $2.8 \times 10^{5}$ & $9.1 \times 10^{15}$ & $139 \mathrm{~ms}$ & 2016 & [36] \\
\hline & InAs & 1.5 & $5.3 \times 10^{3}$ & - & - & 2014 & [37] \\
\hline & InAs & $2-3$ & $4.0-0.6$ & $2.0 \times 10^{12}$ & $\approx 0.1 \mathrm{~ms}$ & 2016 & [38] \\
\hline \multirow{4}{*}{$\begin{array}{c}\text { Hybrid } \\
\text { Heterostructures }\end{array}$} & $\mathrm{PbS}$ QDs/Gr & 0.895 & $1.0 \times 10^{7}$ & - & $0.3-1.7 \mathrm{~s}$ & 2012 & [39] \\
\hline & $\mathrm{PbS}$ QDs/Gr & $0.6-1.4$ & $\begin{array}{c}5 \times 10^{7}-5 \times \\
10^{5}\end{array}$ & $7.0 \times 10^{13}$ & - & 2012 & [10] \\
\hline & B-Si QDs/Gr & $0.4-4$ & $\sim 10^{12}$ & $\sim 10^{13}$ & - & 2017 & [40] \\
\hline & Perovskite/TiO2/Si & 1.1 & 0.87 & $6 \times 10^{12}$ & - & 2017 & [41] \\
\hline
\end{tabular}

\subsection{Quantum Dots and Quantum Wells-Based Photodetectors}

Initially, QW and QD-based IRPDs were considered as the replacements for conventional $\mathrm{Ge}, \mathrm{HgCdTe}$, and related alloys in the mid-waves IR band, realizing their prospects in relatively high operating temperature and chip integration $[31,42,43]$. In practical, quantum wells and dots are defined in sandwiched structures with a well or dot layer capped in barrier layers of conduction-band mismatched materials through epitaxial growth methods (i.e., MOCVD, MBE) as shown in Figure 2a [44,45]. The photo-excited electrons come across the energy barrier which formed between the interface of well or dot layers and barrier layers due to mismatched energy bands. The transition of photo-excited electrons across the interface of well or dot layers and barrier layers enable the detection of light beyond the bandgap limit of the material. Therefore, the broadband IR photodetection in the range of SWIR to FIR have been achieved by tailoring the geometry of such epitaxially grown QWs and dots, and by modifying the interfacial surface chemistry of barriers layers. For efficient light coupling in practical photodetector devices, grooved or surface grating layers on absorption layers have been used [46]. After the invention of the first QD-based photodetectors, several successes have since been made in performance and functionalities $[46,47]$. By using advanced growth techniques and dopant incorporation, different photodetector designs (i.e., dot-in-well (DWELL), quantum cascade) have been brought in to optimize the photodetection performances $[47,48]$. Figure $2 b$ shows typical QW and dot-in-well (DWELL) structures. The enhanced optoelectronic properties and corresponding performance parameters can be achieved by merely tailoring the geometry of either QD or QW structures in these photodetectors. The broad spectral response of quantized GaN/AlGaN superlattice type-II and InAs/InGaAs/GaAs DWELL systems is shown in Figure 2c,d. Moreover, the broad absorption spectral response can also be realized by tailoring the width of the GaN QW layer and in DWELL structure barrier layers resulting in the multiband photo-response spectra $[49,50]$. The multiband photo-response in DWELL structures makes possible the construction of multi-color sensitive photodetectors for thermal image processing. 

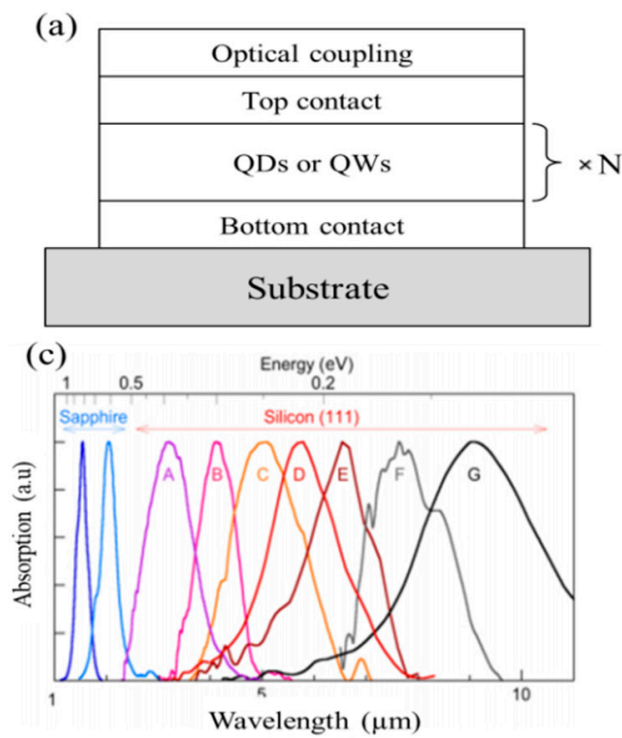

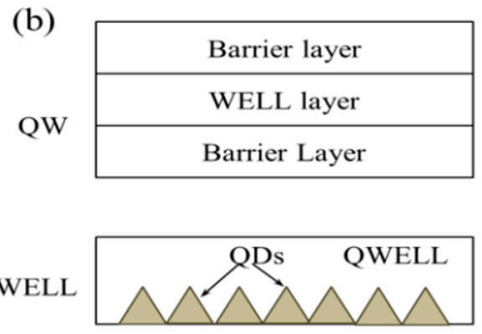

(d)

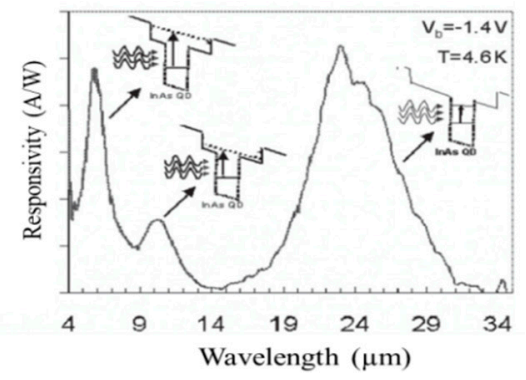

Figure 2. (a) Schematic of QW or QD layers with optical coupling layer and (b) structures of sandwiched QWs with multiple barrier layers and dot-in-well (QWELL) structure, indicated below (c) The tunable absorption in GaN/AlGaN QWs is shown by adjusting the width of the GaN QW layer (reproduced with the permission of Reference [49], Copyright 2009, IOP Publishing). Moreover, (d) shows the multiple band spectral response in a InAs/InGaAs/GaAs dot-in-well structure, (Reproduced with the permission of Reference [50]. Copyright 2007, IEEE).

However, for a successful intraband transition in QWs and QDs for IR detection, heavily-doped semiconductor materials have been used for populating the carriers in the ground state of the desired energy band. Due to such heavy doping, the photodetectors undergo high dark currents, which is undesirable for practical device application and integration of FPAs with readout circuits. Therefore, resonance tunneling barrier layers have been introduced to control the dark and thermally-produced current carriers [51,52]. Moreover, quantum cascade detectors (QCDs) have already been proposed for passive IRPDs. In these photodetectors, asymmetric energy band alignment is used for the mid-wave IR region as well as for even longer wave IR detection [30,53-56].

Rapid development in colloidal quantum dots (CQDs) like PbS [57-59], PbSe [60,61], Ag $2 \mathrm{Se} \mathrm{[62],}$ $\mathrm{HgTe}[63,64]$, and HgSe [20] is providing the promise of an alternative to epitaxially grown QD-based IRPDs in various aspects, such as compatibility with a variety of substrates and cost-effective processing. The typical strong quantum confinement in CQDs has provided unique optoelectronic properties such as ultra-high photoconductive gain achieved through phonons bottleneck effect and surface traps [65-67]. The extensive research efforts in various CQDs synthesis methodologies to define their geometrical structures, stoichiometric composition, and their surface chemistry have improved their optical response span in IR spectra with high electrical performance [68]. The CQD-based photodetectors have high photoconductivity gain as compared to their epitaxially grown counterparts $[35,69,70]$. Recently, a remarkably high detectivity of $\sim 1.8 \times 10^{13}$ Jones at $1.3 \mu \mathrm{m}$ has been reported in PbS CQD-based photodetectors [35]. Most importantly, a unique feature, "multiexciton generation", during light absorption has been explored in CQD-based photodetectors [71,72], which has resulted in optical gain efficiency more than unity $[73,74]$.

Despite their remarkable advantages, performance related issues like poor response time still need serious considerations. It is well known that the native surface oxides result in high detectivity, while at the same time these oxides limit response speed. Therefore, different strategies have been employed to avoid this issue. In the device (Figure 3a), a $350 \mathrm{~nm}$ thin film of PbS CQDs is sandwiched between ITO and $\mathrm{Al}$ electrodes. A depletion region is formed in the device near the $\mathrm{PbS} / \mathrm{Al}$ contact due to the presence of Schottky barrier and remaining part is considered as quasi-neutral region [69]. The carriers are separated due to drift/diffusion mechanisms in both the depletion and quasi-neutral 
region resulted in an acceptable response time with high detectivity. The photoresponsivity depends on the width of the Schottky barrier, and it could be varied by applying an externally biased voltage.

(a)

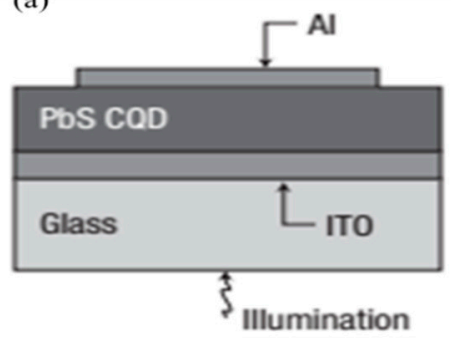

(c)

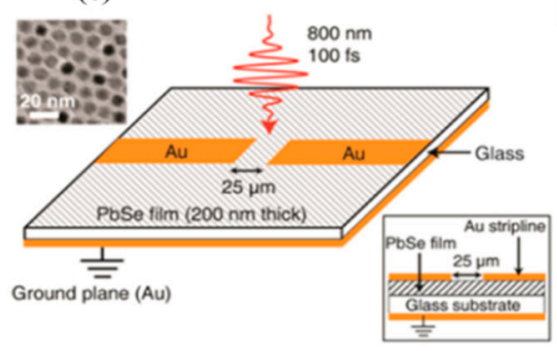

(b)
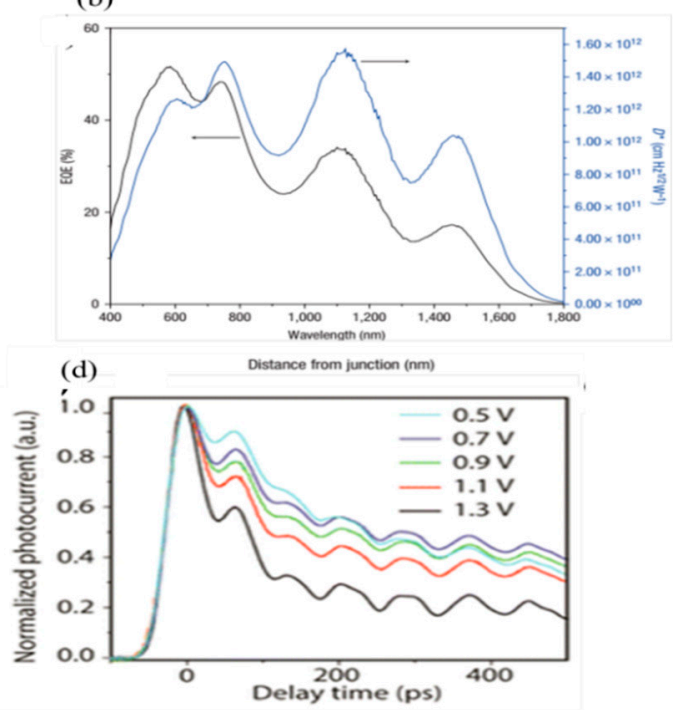

Figure 3. (a) The structure and (b) quantum efficiency of the Schottky diode Al/PbS CQDs of a Schottky diode photodetector based on a PbS CQD film (reproduced with the permission of Reference [69] Copyright 2009, Nature Publishing Group). (c) The structure of a vertically stacked photoconductive detector based on PbSe CQDs and (d) the response time at a different applied voltage (reproduced with the permission of Reference [75], Copyright 2016, American Chemical Society).

In the fully depleted region, a significant photo-response was achieved up to a 3-dB frequency over a wavelength of $\sim 1.5 \mu \mathrm{m}$, while the detectivity was still over $10^{12}$ Jones for this device (Figure $3 \mathrm{~b}$ ). The photo-generated carriers' dynamic and response time in nanoseconds was achieved by applying an external bias voltage. Accordingly, ultrafast current dynamics was accomplished in the ITO/PbSe structure with CQDs / Au contact as shown in Figure 3d. By applying the externally biased voltage, the photo-generated carriers were separated before trapping with the highest response time at $1.3 \mathrm{~V}$ (Figure 3d). In the meantime, to avoid a risk of high dark current, multiple blocking layers were required for performance optimization [76]. The thermal imaging in the mid-wave IR band (3-5 $\mu \mathrm{m})$ and longer waves IR band $(8-12 \mu \mathrm{m})$ was predominantly carried out with traditional $\mathrm{HgCdTe}$ or InAsSb-based focal plane arrays (FPAs).

Recently, the CQDs of low band gap materials such as HgTe [77] and HgSe [20,78] have also been synthesized. Cut-off wavelengths have been achieved up to $12 \mu \mathrm{m}$ in HgTe CQD-based IRPDs [75,79]. Figure $4 \mathrm{a}$,b show the size and absorption spectra of HgTe CQDs in the range of $15 \mathrm{~nm}$ to $20 \mathrm{~nm}$, and an absorption gap of $5 \mu \mathrm{m}$ to $8 \mu \mathrm{m}$ wavelength at room temperature. Moreover, the absorption in the longer wavelength of $\sim 8-12 \mu \mathrm{m}$ can also be achieved by cooling to liquid nitrogen temperature. Recently, HgSe CQD-based photodetectors have successfully fabricated for NIR to the THz range with significantly extended absorption edges up to $20 \mu \mathrm{m}$ at room temperature [20]. From Figure 4c, it is clear that typical intraband transition appears between $500 \sim 3000 \mathrm{~cm}^{-1}$. The sharp peaks in IR absorption bands in HgSe CQDs indicate discrete quantum states, while the continuously tunable behavior in the range of $3 \mu \mathrm{m}$ to $20 \mu \mathrm{m}$ wavelength was observed by varying the size of CQDs. Therefore, practically assembled photodetectors based on CQDs has shown promising photodetection performance over $1 \times 10^{8}$ Jones at of $\sim 6 \mu \mathrm{m}$ wavelength (Figure $4 \mathrm{~d}$ ). 
(a)

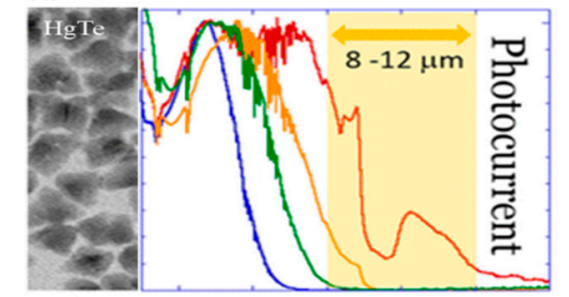

(c)

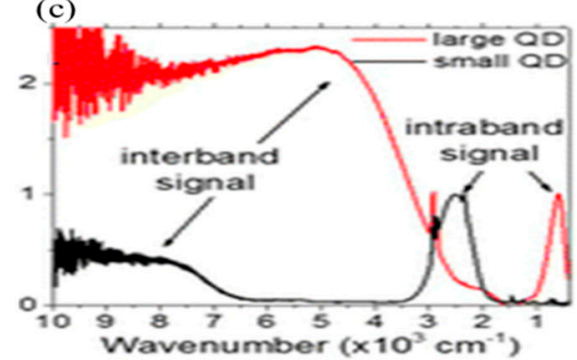

(b)
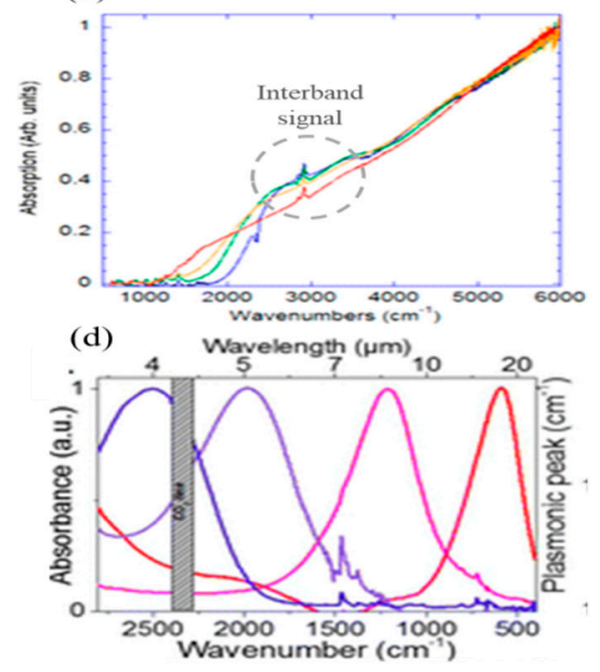

Figure 4. (a) TEM image of HgTe CQDs with broadband photo-response; (b) shows the electron transitions for corresponding wavenumbers (reproduced with the permission of Reference [75], Copyright 2014, American Chemical Society); (c) The intraband transition spectra and (d) absorption spectra in HgSe CQD-based photodetectors (reproduced with the permission of Reference [20], Copyright 2016, American Chemical Society).

\subsection{Nanowires}

One-dimensional (1D) nanostructures such as NWs and NTs have attracted significant research interest in the field of optoelectronic devices (i.e., lasers, photodetectors) [80]. The photoconductive gain mechanism in 1D and CQD structures is the same due to their similar surface to volume ratio. The inherent anisotropic nature of nanowires renders fast carrier mobility and the feasibility in constructing polarization sensitive photodetectors. The III-V semiconductor NWs have attracted considerable research interest due to their direct bandgap and high carrier mobilities [81-83]. In addition to conventional semiconductor nanowires, the polymer-based optical nanowires attract a significant research interest considering importance in optical applications and functionalities (e.g., optical intensity, wavelength, polarization, phase, and fluorescence) [84-86]. The protein-based single nanowires and nanowire devices could be readily fabricated by using femtosecond laser direct writing (FLDW) [87-92]. Recently, the one optical window of the protein single nanowire waveguides at $\approx 680 \mathrm{~nm}$ coinciding with the red or near-IR biological window has been reported [93,94]. The significant merits, such as versatility, facilely adjustable high sensitivity, biocompatibility, satisfactory designability, and repeatability of nanowire-devices may endow the all-protein-based single nanowire biosensors with potential applications in bio-X environments.

Recently, ultra-high photocurrent gain was reported in GaN NW-based photodetectors at room temperature, which is three times higher than those for their thin-film counterparts. Furthermore, ultra-high photo-response ( $\sim \mathrm{ps})$ in mid-wave IR with high mobility at room temperature was reported in core-shell NWs (e.g., InGaN InAs/InP, InAs/InAsSb) based photodetectors [95-98]. In Figure 5c, along with the same InAs NW, an Ohmic-Ohmic contact was fabricated using $\mathrm{Cr} / \mathrm{Au}$ as electrodes, due to different work functions as a Schottky barrier achieved at the contact interface. As shown in the Figure $5 c, d$, the dark and photocurrent measurements with the aforementioned Ohmic and Schottky barrier combinations in the device, respectively, whereas in the Schottky-Ohmic contact, a depletion region developed in the InAs NW, resulting in a significant decrease in dark current. Also, the built-in electrical field at contact interface also enhances the charge separation efficiency. Therefore, in InAs nanowire-based photoconductors, a high photo-response up to $5.3 \times 10^{3} \mathrm{AW}^{-1}$ was achieved at $1.5 \mu \mathrm{m}$ by adopting the Schottky contacts. 
(a)

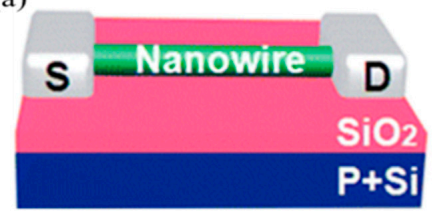

(c)

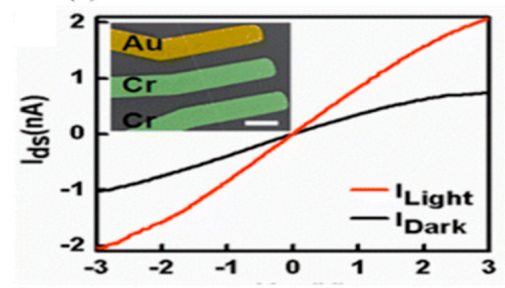

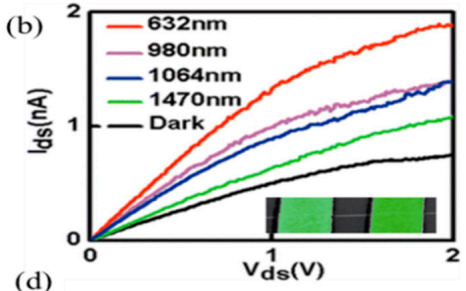

(d)

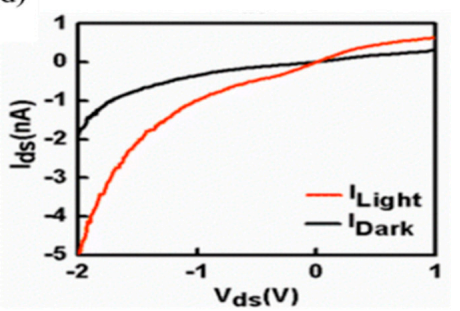

Figure 5. (a) Schematic illustration of an InAs NW-based photodetector; (b) photocurrent spectra of an InAs NW near-infrared photodetector changing from red to NIR light and the inset is the SEM image of a representative photodetector; (c) the dark and photocurrent at ohmic-ohmic combinations in the detectors and the inset shows $\mathrm{Au} / \mathrm{Cr}$ contact as electrodes; (d) the photo-response at the Schottky-Ohmic contact combination (reproduced with the permission of Reference [37], Copyright 2014, American Chemical Society).

Besides Schottky contacts, dopant gradient mechanism in NWs were also used to improve the on-off ratio and suppress the dark current in III-V NW-based IRPDs [11,12,83]. Figure 6a shows a schematic of InAsSb NW-based photodetectors. The $\mathrm{p}-\mathrm{i}-\mathrm{n}$ type junction was realized by dopant incorporation during the vapor phase growth of NWs. The cascade-like energy band alignment in InAs $_{1-x} \mathrm{Sb}_{\mathrm{x}} \mathrm{NW}$ formed along the dopant gradient direction (shown in Figure $6 \mathrm{~b}$ ). The built-in $\mathrm{p}-\mathrm{i}-\mathrm{n}$ junction in photodetectors works like a photovoltaic mode, which possesses the negligible risk of dark current (Figure $6 \mathrm{c}$ ). The most extended wavelength detection of $\sim 2.5 \mu \mathrm{m}$ was reported in InAs $\mathrm{s}_{1-\mathrm{x}} \mathrm{Sb}_{\mathrm{x}}$ NW-based photodetectors at room temperature (Figure 6d). Here, the photogate effect took place by the accumulation of a carrier on the InAs NW surface due to native oxides, which significantly improved the carrier mobility and detectivity [17-20].

(a)

(c)
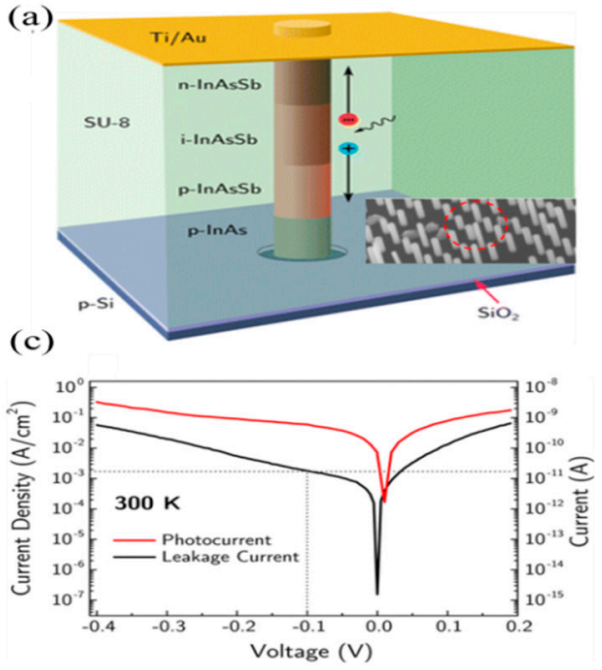

(b)

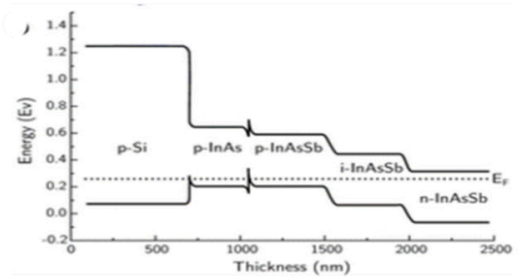

(d)

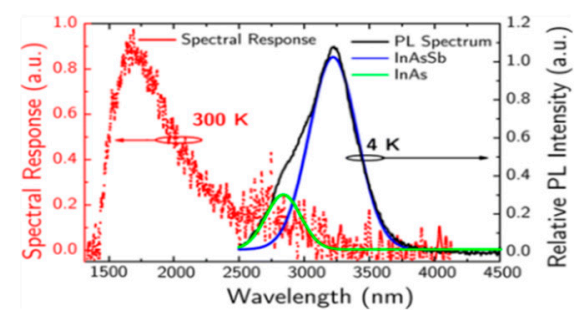

Figure 6. (a) The schematic of $\operatorname{InAs}_{1-\mathrm{x}} \mathrm{Sb}_{\mathrm{x}}$ nanowire with $\mathrm{p}-\mathrm{i}-\mathrm{n}$ junction vertically and the inset is the SEM image of NWs array on a p-Si substrate; (b) shows the cascade-like energy band alignments along the NW at different stichometry (x) values; (c) dark and photocurrents corresponding to $1.55 \mu \mathrm{m}$ infrared light, and (d) the photo-response at different temperature in an InAs $\mathrm{s}_{1-\mathrm{x}} \mathrm{Sb}_{\mathrm{x}}$-based photodetector. (Reproduced with the permission of Reference [11]. Copyright 2016, American Chemical Society). 
A reverse photo-response effect in an InAs nanowire-based photodetector was also observed under optical illumination [99,100]. A high detectivity of $\sim 2 \times 10^{12}$ Jones and a photo-response speed of $\sim 80 \mu \mathrm{s}$ was achieved at $2 \mu \mathrm{m}$ in InAs NW-based photodetectors by taking advantage of such reverse photo-response phenomena [38]. The optically triggered carrier separation mechanism in InAs NW-based photodetector is shown in Figure 7a. The photocarriers were generated under illumination of a relatively shorter wavelength $(\sim 50 \mathrm{~nm})$, lower than the absorption band. Meanwhile, the generated carriers were trapped in the surface native oxides, and the remaining holes were expected to combine with the electrons in the core of the NW, so that the dark current was suppressed. As shown in Figure 7c, initially there was no photo-response observed at $2 \mu \mathrm{m}$. Once an InAs nanowire was illuminated with a shorter wavelength light as a precursor, the dark current was suppressed due to the negative response throughout the photodetection process.

(a)

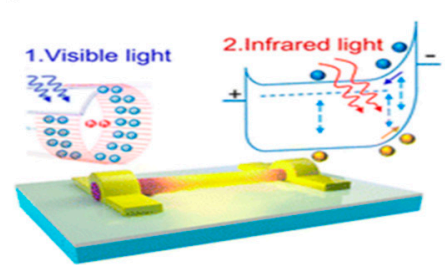

(c)

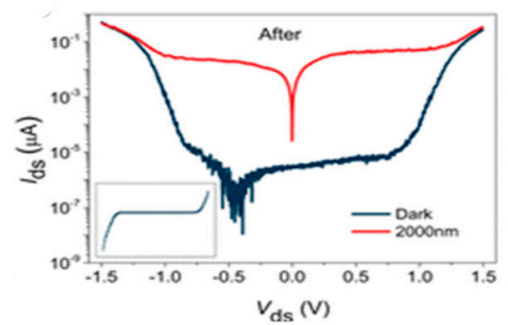

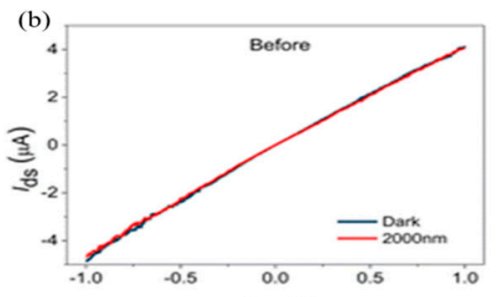

(d)

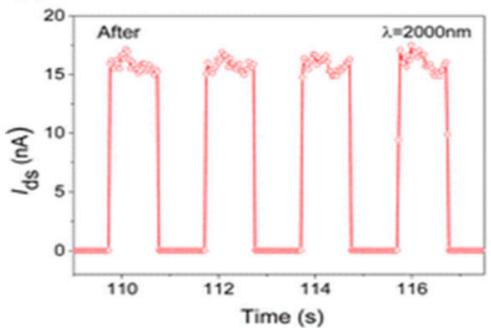

Figure 7. The reverse photo-response triggered IR detection in an InAs nanowire-based photodetector. (a) The single InAs nanowire with photo-gating mechanism under shorter wavelength illumination; (b) the photo-response before and (c) after shedding of light; (d) the photo-response measurement after optical activation indicating fast response speed about $100 \mu$ in the device, (reproduced with the permission of Reference [38]. Copyright 2016, American Chemical Society).

Besides semiconducting nanowire-based infrared photodetectors, single-photon detectors based on superconducting nanowires (SNSPDs) have rapidly emerged as a highly promising and new class of photon counting technology down to the near- and mid-IR ranges [101,102]. These devices offer high efficiency, provided by orders of magnitude lower energy gaps, less noise, and excellent timing resolution. Although in visible to NIR range, there exists commercially available single-photon detectors, but they also unusable due to a rapid decrease in sensitivity.

The liquid-helium cooling requirement, relatively small active area, and low sensitivity above $2 \mu \mathrm{m}$ are the main disadvantages of conventional SNSPDs, limiting their applications especially at the near-IR. Various SNSPDs are operated in the ultra-low temperature range of $1.7-5 \mathrm{~K}$, because these are based on conventional, metallic superconductors like $\mathrm{NbN}, \mathrm{NbTiN}, \mathrm{Nb}$, or WSi [103].

Superconducting nanowire single-photodetector (SNSPD) development would not be possible without the progress made over the past decade in nanotechnology, and in particular, in nanopatterning of superconducting thin films. A typical SNSPD consists of a few nanometers of a superconducting materials of thin films in sub-micrometers. In SNSPD, the energy of the absorbed photon is distributed through an avalanche-like process, creating a nonequilibrium population of quasiparticles. This quasiparticle population then disrupts the supercurrent flow, resulting eventually in a detection event. Therefore, the broadband IR photodetection in the range near- to mid-IR range has been achieved by tailoring the geometry of thin film and by using more than one thin layer of superconducting 
materials. After the invention of the first operational SNSPD in 2001 by Gol'tsman et al. [104], several successes have since been made in term of performance and functionalities [105,106]. By using advanced deposition techniques and device geometries, several advanced SSPDs designs (i.e., meandering-shaped SNSPD, multiple parallel-nanowire-based SNSPD, as shown in Figure 8a,b) have been brought in to optimize photodetection performance and functionalities [106-110]. Mattioli et al., presented a detailed review of superconducting nanowires for single photon detection particularly in the spectral range above $1 \mu \mathrm{m}$ [111]. A significant response at $1480 \mathrm{~nm}$ and $1525 \mathrm{~nm}$ have been achieved in the two front-side-coupled silver dipole $\mathrm{NbN}$ nanoantenna, and $50 \%$ to $130 \%$ in the system detection efficiency was observed (as shown in Figure 8a,b). The superconducting nanowire coupled with plasmonic nanostructures offers a pathway to increase absorption, creating larger active areas and achieving more efficient detection at longer wavelengths. Furthermore, in $\mathrm{NbN}$ based multiple nanowires (with a width $50 \mathrm{~nm}$ ) connected in parallel (as shown in Figure 8b) resulted in 10 times better quantum efficiency at $3.5 \mu \mathrm{m}$ wavelength than conventional SNSPDs [112].

(a)

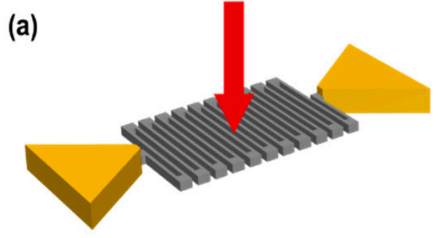

(c)

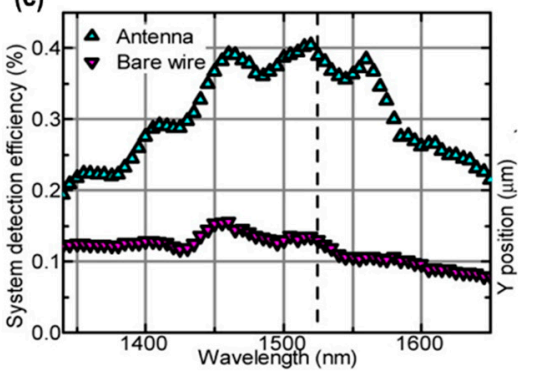

(b)

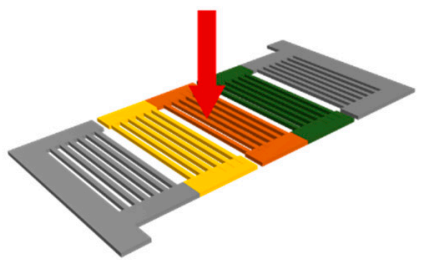

(d)
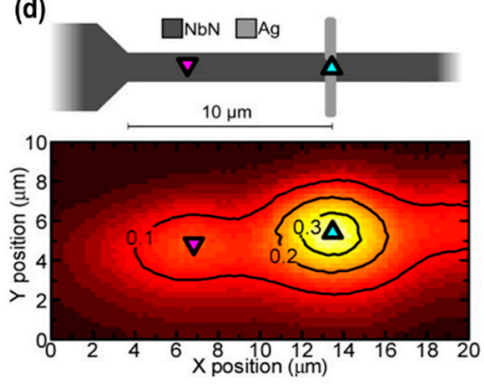

Figure 8. Shows the typical (a) meandering nanowire and (b) parallel-meandering nanowire single-photon detector. (c) The polarization at which the $\lambda_{\text {res }}=1525 \mathrm{~nm}$ nanoantenna and wire respond best are selected and (d) the mapping of the nanowire when the incident light is polarized with the electric field, such that the so-called antenna polarization rotates to give the highest response from the antenna-the antenna's best polarization (reproduced with the permission of Reference [113], Copyright 2015, American Chemical Society).

\subsection{Black Phosphorus, Graphene, and Heterostructures}

The recently emerging 2D materials represented by graphene and black phosphorus (BP) are attracting intensive attention in IR detection technologies $[6,7,114-116]$. The thin atomic thickness of $2 \mathrm{D}$ materials possess strong out of plane quantum confinement, the optoelectronic properties of these materials are prone to be modified by the number of layers stacked and their stack sequence [117]. The thin atomic thickness of 2D materials give excellent tolerance to external strains, making the 2D materials especially attractive as the building blocks in flexible electronics [118-120]. Moreover, the electronic properties of 2D materials are found feasibly tuned by field effects and strains $[119,120]$, which could be exploited for their engineering in photodetector devices. For infrared photodetection, graphene and black phosphorus are mostly explored because their broadband absorption to low energy infrared photons. For the construction of electronic devices, the ultrathin exfoliated 2D flakes are transferred to arbitrary substrates using various wet and dry methods [121,122].

It is found that at atomic layer thickness, graphene absorbs $2.3 \%$ of incident photons without significant wavelength dependence. In photodetectors, its absorption efficiency could be improved by stacking multilayers or by engineering graphene into other nanostructures, such as nanodisks $[123,124]$. 
With large carrier mobility (up to $2.5 \times 10^{5} \mathrm{~cm}^{2} \mathrm{~V}^{-1} \mathrm{~s}^{-1}$ ) and ultrafast carrier dynamics ( $\sim \mathrm{ps}$ ) [125-128], graphene-based photodetectors are possible to work with at the extremely high frequency of $500 \mathrm{GHz}$ [129]. In practical graphene-based devices, various strategies have been employed for effective separation of the photo-excited carrier in such short timescales, for example, metal-graphene junction, tunneling barrier junctions, and graphene homogeneous $\mathrm{p}-\mathrm{n}$ junctions $[6,130]$.

Rather than making any Schottky contacts or $\mathrm{p}-\mathrm{n}$ junctions, the photogenerated carriers can be separated naturally by type-II band alignment in heterostructures. Notably, in hybrid heterostructures, comprehensive merits of individual materials integrated into a single device can be utilized to achieve optimized performance. For example, graphene possesses high electron mobility, while the overall IR absorption efficiency is much lower, whereas the PbS CQDs have a larger extinction coefficient. An ultra-high photoconductive gain $\left(\sim 10^{8}\right)$ has been achieved by integrating graphene with CQDs into a single device [10,40]. Moreover, a unique feature in hybrid heterostructure-based photodetectors is the photogenerated carriers separated at the surface interface. The direct separation of photogenerated carriers could be realized in such kinds of device architecture due to type-II band offsets $[39,131,132]$. For the optical sensitization of ultrathin semiconductors (i.e., graphene, black phosphorus), several high-extinction co-efficient nanostructures (i.e., QDs, nanosheets [10,39]) as well as some organic dyes molecules have been used to achieve high-performance devices with different functionalities [133-136]. Recently, a significant photoresponsivity $10^{7} \mathrm{AW}^{-1}$ in the NIR region were reported in PbS CQDs/graphene hybrid heterostructure-based photodetectors [10]. The light absorption occurs in the PbS CQD layer, and the carrier transport is taking place in the graphene layer (as shown in Figure 9a). The photogenerated carriers are expected to separate at the CQD/graphene layer interface due to band misalignment. In this case the electrons are retained in the CQD, whereas holes are injected in the graphene layer. The injected holes are combined with the electrons in the graphene layer, which results in a strong photogate effect. Therefore, a high gain $\left(\sim 10^{8}\right.$ electrons per photon absorption) has been accomplished by modulating electrical conductance of the graphene layer.
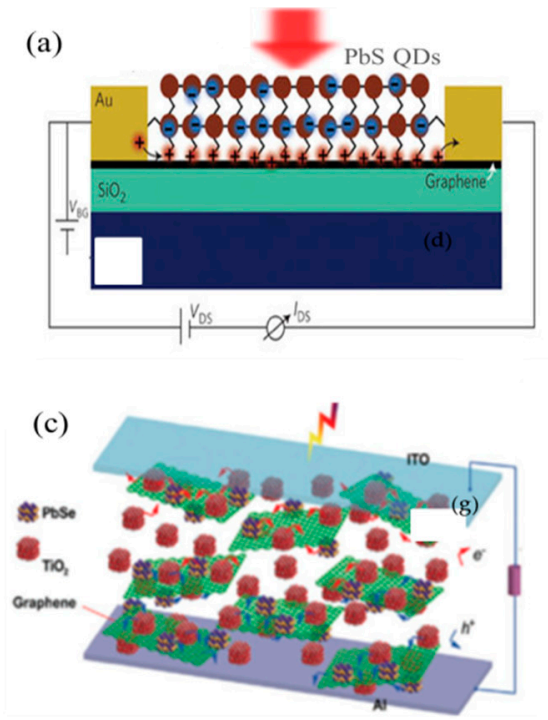

(b)

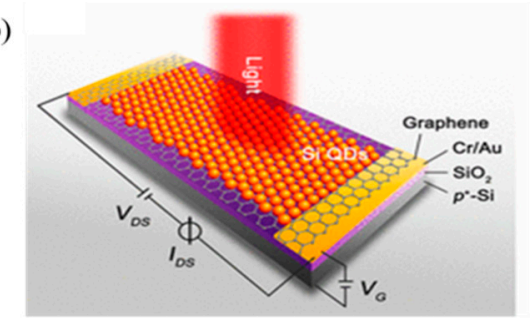

(d)

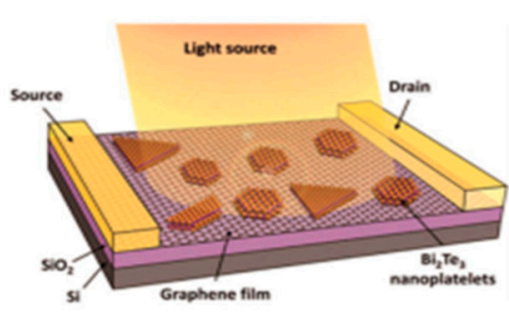

Figure 9. Schematics of different hybrid phototransistors based on heterostructure combinations. (a) PbS CQDs/graphene structure (reproduced with the permission of Reference [10]. Copyright 2012, Nature Publishing Group); (b) B-doped Si QD/graphene, shows the intense near-field absorption associated with the Localized Surface Plasmon Resonance (LSPR) of B-doped Si QDs (reproduced with the permission of Reference [40]. Copyright 2016, American, Chemical Society); (c) $\mathrm{PbS} / \mathrm{TiO}_{2} /$ graphene multi-interface heterostructures (reproduced with the permission of Reference [133] Copyright 2012, Wiley-VCH); (d) $\mathrm{The} \mathrm{Bi}_{2} \mathrm{Te}_{3}$ nanoplatelets/graphene heterostructure-based photodetector (reproduced with the permission of Reference [134], Copyright 2015, American Chemical Society). 
Recently an extra-sensitive MWIR band photodetection was achieved using boron (B)-doped Si (Si:B) QDs (shown in Figure 9b) [40]. The extinction coefficient of graphene was relatively enhanced directly by the LSPR of the Si:B QDs, which was one of the unique features of this particulate structure. The electron-transition based optical absorption took place in the Si:B QDs in the ultraviolet (UV) to near-infrared (NIR) regions that additionally led to photogating in the graphene layers resulting in gain in the MIR band. Therefore, the ultra-broadband (UV-MIR) photodetection was achieved in Si:B QDs/graphene structures with a high responsivity up to $\sim 10^{9} \mathrm{AW}^{-1}$, gain up to $\sim 10^{12}$, and detectivity of $\sim 10^{13}$ Jones. Thus, by tuning the geometry and materials' properties as well as the surface chemistry of QDs, a significant spectral response from shorter to longer wavelengths was achieved. In recent years, several hybrid heterostructures have been developed, like Ge/graphene [137], $\mathrm{PbSe} / \mathrm{MoS}_{2}$ [132], and $\mathrm{HgTe} / \mathrm{MoS}_{2}$ [138], owning significantly high responsivity in the range of visible to different IR bands. Besides single heterojunction structures, heterostructures with multiple interfaces are now prevalent due to their high detectivity and responsivity in the NIR spectrum [41]. Recently, the $\mathrm{TiO}_{2} / C Q D s /$ graphene based heterostructure has also been investigated (Figure 8c) [133]. Such kinds of structure show a high detectivity reaching up to $10^{13}$ Jones in the NIR region, but still keep a fast response in a few microseconds. Therefore, from such performance-related developments, it can be anticipated that there will be a remarkable potential to optimize the performance of hybrid heterostructures. The synergistically engineered heterostructures after a comprehensive understanding of optical and electrical properties of materials would provide leverage for photodetection performance in different IR bands.

\subsection{Plasmonic Nanostructures and Related Architectures}

Over the last two decades, continuously researches have been carried out about light-matter interaction, particularly in nanostructured photodetection devices. The photodetection performance has been seemingly approaching the intrinsic performance limitation of materials. Therefore, the plasmonic nanostructures and plasmonic meta-surfaces are now attracting much attention to prospective photo-detection technologies. Surface plasmon interactions can typically be divided into (i) localized surface plasmons (SPs) and (ii) surface plasmon-polaritons (SPPs). For both, the incident light wave is coupled with charge carriers in the metal by EM field, and this belted oscillation takes place at the metal/dielectric interface. This optically executed surface plasmon resonance (SPR) exponentially decayed in dielectric media, wherein the light absorption takes place $[25,139,140]$. The surface plasmons decay along the interface is exhibiting the light waveguide pathway [141]. Such propagating SPPs optically resonated with similar frequency. The resonance frequency depends on the geometrical structure and surrounding environment of the plasmonic nanostructure $[142,143]$. This unique feature of plasmonic nanostructures would provide a distinctive perspective in optoelectronic and photovoltaic devices [144,145]. Now several fabrication methods are possible for precise design of plasmonic nanostructures, such as lithography, ion beam milling, chemical synthesis routes and nano-imprinting [146].

Recently, the hot electron-based photodetection was demonstrated at sub-bandgap in semiconducting materials integrated with a nanostructured plasmonic antenna array. Under optical illumination, the hot electrons were generated from the surface plasmon decay and injected into the semiconductor layer, which resulted in photodetection with an additional bandwidth [145-148]. Figure 10a shows a photodetector based on $\mathrm{MoS}_{2}$ as a semiconducting layer with a nanostructured $\mathrm{Au}$ electrode. A Schottky barrier was developed due to a different work functions at the $\mathrm{MoS}_{2} / \mathrm{Au}$ interface. Upon light irradiation, hot electrons generated by SPs, came across the Schottky barrier and were absorbed in the $\mathrm{MoS}_{2}$ layer, which resulted in a high gain $\left(\sim 10^{5}\right)$ in the NIR band (shown in Figure 10b). It is known that due to energy bandgap $\mathrm{E}_{\mathrm{g}}=1.65 \mathrm{eV}$, the photo-response was not found in $\mathrm{MoS}_{2}$. The absorption of light depends on external biased voltage as shown in Figure 10b. A maximum photo-response was observed in $\sim 1.1-1.2 \mu \mathrm{m}$ when the external bias lies within the injection and extraction range. 
(a)

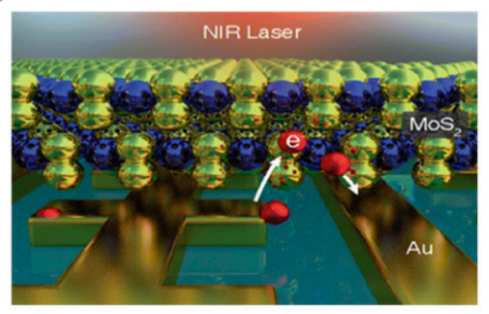

(c)

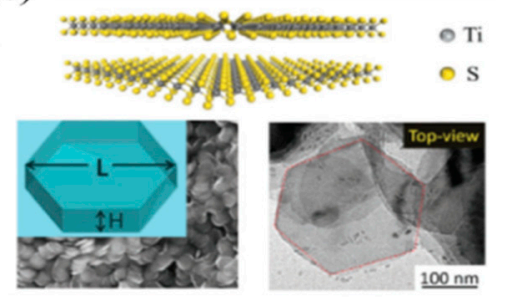

(b)

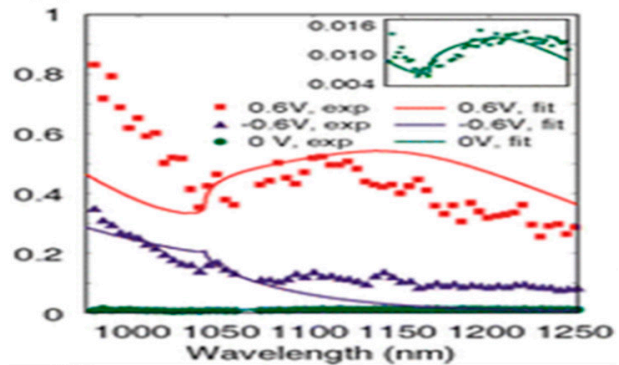

(d)

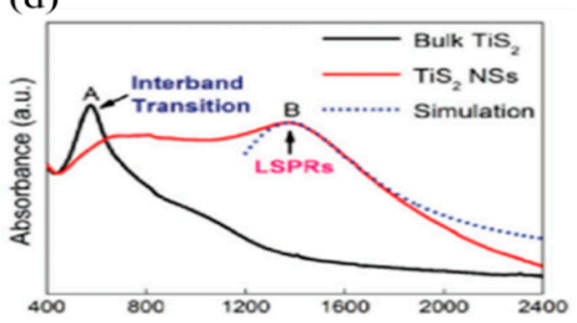

Figure 10. (a) The schematic of Hot Electron-Based Near-Infrared Photodetection Using Bilayer $\mathrm{MoS}_{2}$; (b) the photo-responsivity of the photodetector in the NIR-band under different biased voltages (Reproduced with the permission of Reference [147]. Copyright 2015, American Chemical Society); (c) the schematic illustration and morphologies of $\mathrm{TiS}_{2}$-based nanoplatelets; (d) the SPR enhanced spectral response in the NIR-band (Reproduced with the permission of Reference [149]. Copyright 2016, Wiley-VCH).

Beside metallic elements, several semi-metals or heavily-doped semiconductors like ITO, $\mathrm{TiS}_{2}$, and materials with high carrier concentrations have also been suggested for surface resonance beyond NIR $[149,150]$. It has been reported that the surface plasmon resonance at relatively larger NIR band edges in semi-metallic $\mathrm{TiS}_{2}$ with the nanodisks type of morphology could realize the surface plasmon resonance (SPR) effect in the telecommunication band $1.5 \mu \mathrm{m}$ [149]. Figure 10c is illustrating the schematic of the structure of $\mathrm{TiS}_{2}$ layer with nanodisks type structural morphology. Additionally, a broadened hump immerged in the absorption spectra (Figure 10d), indicating the plasmon resonance induced in $\mathrm{TiS}_{2}$ nanostructures, which resulted in a broadband photo-response up to $\sim 2.4 \mu \mathrm{m}$ wavelength.

It is known that the optical response in the far-field is governed by the near-field properties of the surface plasmon resonance. By utilizing the SPR feature of metal or semi-metallic nanostructures, the photo-response capabilities of photodetectors have significantly improved, and various efforts have been devoted to enhancing and guiding the far-field EM radiations at the subwavelength level [148,151]. For successful coupling of light to SPP, different strategies have been adopted such as grooved surface texture, surface gratings, and metal-disks or porous structures [148,152]. These structures have also been used to optimize absorption efficiency in CQDs and other 2D structure as discussed in an earlier section $[77,153,154]$. Therefore, by exploiting the SPR feature of Au layers, an exceptionally enhanced photo-response has been achieved in HgSe CQD-based photodetectors between the MWIR and LWIR spectrum [34].

Moreover, grooved surface grating and plasmonic structures provide an intense field near their peripheries which would enhance the extinction coefficient at the optical band gap edge $[108,110,113]$. The micro-integration of plasmonic nanostructures on the chip is difficult because of the readout in the far-field. It would be a more desirable situation to monitor the far-field signals indirectly by near-field variations. Ho et al., developed a promising strategy to focus, confine, and guide the far-field efficiently in a small volume by coupling LSPR and stationary surface plasmons [155]. Figure 10a shows the schematic of metallic U-shaped cavities, which are separated by semiconductor (Si) vertical channels, and a SEM image at the right side of Figure 10a(i) shows the cross-section of these channels on the substrate. The semiconductor channel acts as a dielectric between metallic cavities forming 
a capacitor-like structure. The irradiated light is focused in the channel by the LSPR at the tops of the nano-fins which are then guided and confined on the channel boundaries vertically by the SPR, which can be observed by simulation studies (as shown on the right side of Figure 11a(ii). The incident light is concentrating on the channel without much leakage and is efficiently converted into photocarriers which results in impedance modulation of the structure. The plasmonic coupled modes show narrow bandwidths and strong absorption at point $\mathrm{A}$ with peak wavelength centered at about $1.59 \mu \mathrm{m}$ (Figure 11b). The more important thing here is reflectance and absorptance bandwidth, and intensity depends upon nanochannel cross-sectional width and material. Likewise, with various particular designs of a metal coupler, spectral selectivity has been transformed into polarization and color detection $[148,152,156]$.

(a)

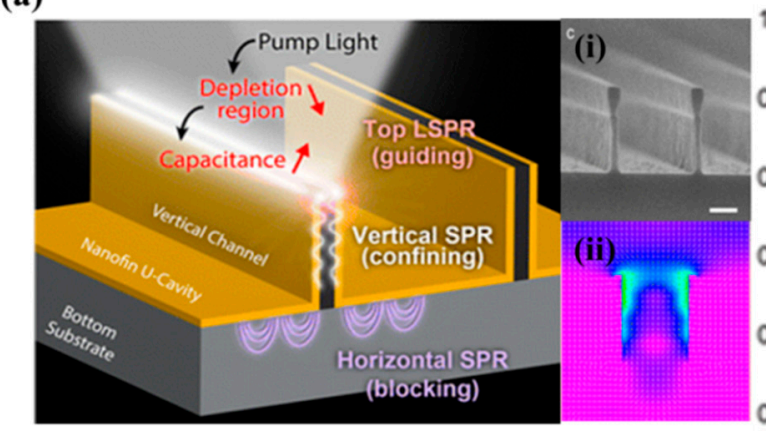

(b)

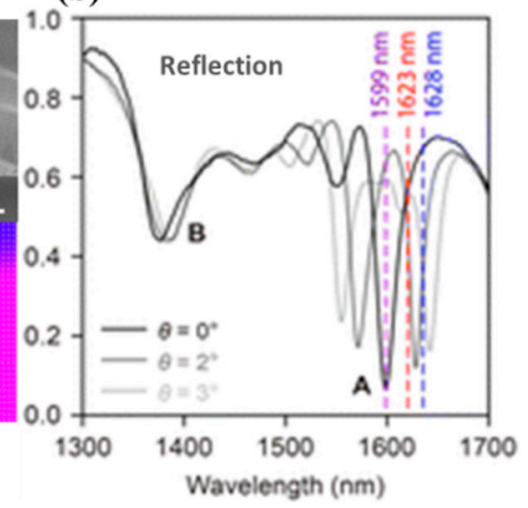

Figure 11. Three-dimensional plasmonic nanochannel/semiconductor structure. (a) Nanochannel/ semiconductor with U-shaped vertical plasmonic cavities structured at semiconductor substrate, (i) SEM image of $\mathrm{Si}$ channel fin on $\mathrm{SiO}_{2}$ substrate, (ii) simulation of light concentration of EM radiations at right side; and (b) optical spectra showing the plasmonic coupled mode at different angles $(\theta)$ (Reproduced with the permission of [156], Copyright 2016, American Chemical Society).

\section{Summary}

In this review, we have briefly surveyed recent developments in the field of IRPDs based on different nanostructured materials which are considered essential building blocks due to various exclusive optoelectronic properties associated with their geometrical structures. We have also observed several achievements in the performance and functionalities of IRPDs regarding detectivity, responsivity, and polarization sensitivity. Such achievements are realized with optimization of carrier dynamics in nanostructured materials by feasible tailoring of the optical band gap of quantized systems, and nano-fabrication of polarization sensitive anisotropic materials and architectures. In Figure 12, responsivity values of the representative nanostructured materials are selected from Table 1 and plotted versus their detection wavelengths. Due to the broadband nature of infrared spectra, there are hardly materials that could fulfil all the requirements of IR detection from NIR to FIR. As displayed in the figures, the nanostructured materials represented by quantum dots, nanowires, and hybrid materials are showing unprecedented high performances in the NIR to SWIR bands. This is benefited from the feasible engineering of photoconductive gain mechanisms, e.g., by surface tailoring, field effect modulations or building heterojunctions.

Although several great successes have been achieved, some challenges are still in the way to achieve optimized performance in IRPDs, like the paradoxical relation between optical gain and response time, and wavelength detection limit and operational temperature. However, the hybrid heterostructure combinations are likely to play essential roles in perspective high-performance IRPDs with regards to the challenges discussed. Moreover, the integration of traditional low-dimensional nanostructured materials with plasmonic nanostructures and plasmonic waveguides is crucial for the construction of photodetectors beyond the optical detection limit of a particular material. Therefore, 
considering the significant achievements in nanotechnology with a variety of materials, we are expecting the bright future of IRPDs based on nanostructured materials.

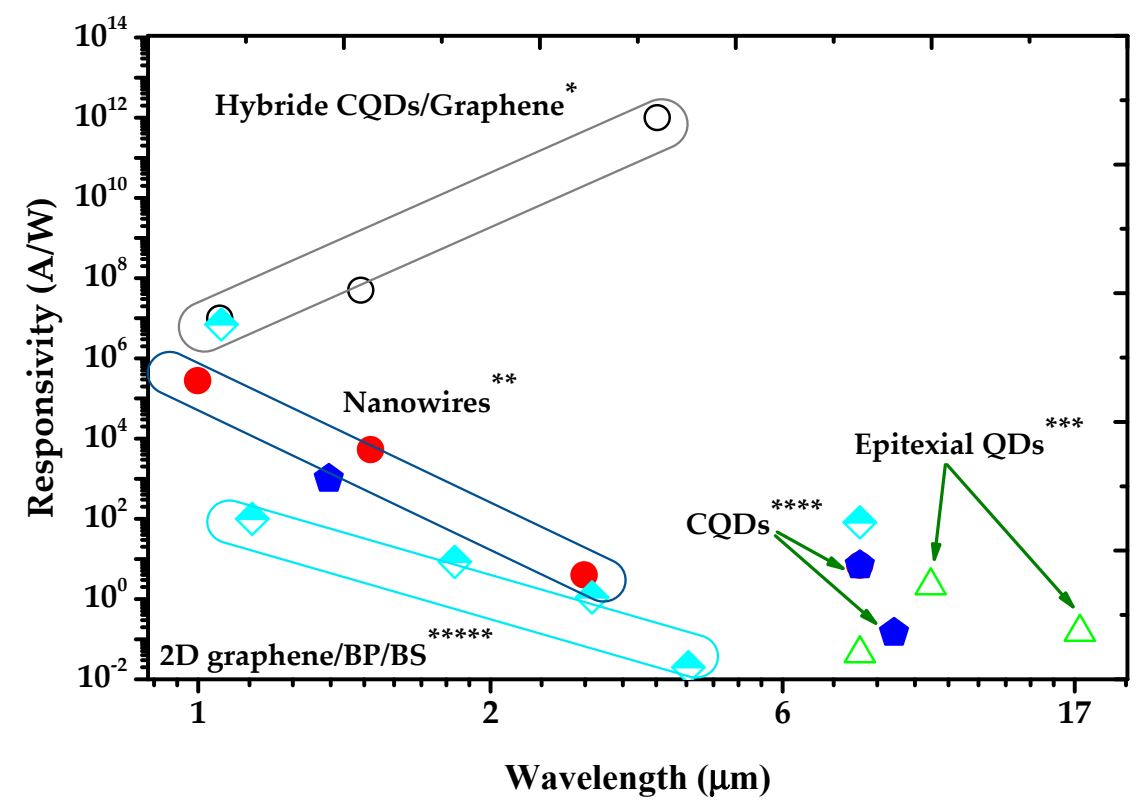

Figure 12. A summary of the responsivity of infrared photodetectors based on different nanostructured materials versus the detection wavelength $[10,39-41]^{*} ;[36-38]^{* *} ;[28-31]^{* * *} ;[33-35]^{* * * *} ;[153,157-159]^{* * * * *}$.

Funding: This work is supported by the National Natural Science Foundation of China (Grant No. 51372032).

Acknowledgments: The authors would like to thank Dr. Tayiba Ilyas (Institute of Fundamental and Frontier Sciences, UESTC) and Dr. Abubakar (School of Electronic Science and Engineering, UESTC) for their kind help.

Conflicts of Interest: The authors declare no conflicts of interest.

\section{References}

1. Dawes, D.G.; Turner, D. Some Like It Hot | Features I Photonics Spectra. December 2008. Available online: https:/ /www.photonics.com/Article.aspx?AID=35976 (accessed on 14 May 2018).

2. Konstantatos, G.; Sargent, E.H. Nanostructured materials for photon detection. Nat. Nanotechnol. 2010, 5, 391-400. [CrossRef] [PubMed]

3. Lefèvre, F.; Forget, F. Observed variations of methane on Mars unexplained by known atmospheric chemistry and physics. Nature 2009, 460, 720-723. [CrossRef] [PubMed]

4. Saran, R.; Curry, R.J. Lead sulphide nanocrystal photodetector technologies. Nat. Photonics 2016, 10, 81-92. [CrossRef]

5. Chitara, B.; Panchakarla, L.S.; Krupanidhi, S.B.; Rao, C.N.R. Infrared Photodetectors Based on Reduced Graphene Oxide and Graphene Nanoribbons. Adv. Mater. 2011, 23, 5419-5424. [CrossRef] [PubMed]

6. Koppens, F.H.L.; Mueller, T.; Avouris, P.; Ferrari, A.C.; Vitiello, M.S.; Polini, M. Photodetectors based on graphene, other two-dimensional materials and hybrid systems. Nat. Nanotechnol. 2014, 9, 780-793. [CrossRef] [PubMed]

7. Zhou, X.; Gan, L.; Zhang, Q.; Xiong, X.; Li, H.; Zhong, Z.; Han, J.; Zhai, T. High performance near-infrared photodetectors based on ultrathin SnS nanobelts grown via physical vapor deposition. J. Mater. Chem. C 2016, 4, 2111-2116. [CrossRef]

8. Youngblood, N.; Chen, C.; Koester, S.J.; Li, M. Waveguide-integrated black phosphorus photodetector with high responsivity and low dark current. Nat. Photonics 2015, 9, 247-252. [CrossRef]

9. Gao, J.; Nguyen, S.C.; Bronstein, N.D.; Alivisatos, A.P. Solution-Processed, High-Speed, and High-Quantum-Efficiency Quantum Dot Infrared Photodetectors. ACS Photonics 2016, 3, 1217-1222. [CrossRef] 
10. Konstantatos, G.; Badioli, M.; Gaudreau, L.; Osmond, J.; Bernechea, M.; de Arquer, F.P.G.; Gatti, F.; Koppens, F.H.L. Hybrid graphene-quantum dot phototransistors with ultrahigh gain. Nat. Nanotechnol. 2012, 7, 363-368. [CrossRef] [PubMed]

11. Thompson, M.D.; Alhodaib, A.; Craig, A.P.; Robson, A.; Aziz, A.; Krier, A.; Svensson, J.; Wernersson, L.-E.; Sanchez, A.M.; Marshall, A.R.J. Low Leakage-Current InAsSb Nanowire Photodetectors on Silicon. Nano Lett. 2016, 16, 182-187. [CrossRef] [PubMed]

12. Huh, J.; Yun, H.; Kim, D.-C.; Munshi, A.M.; Dheeraj, D.L.; Kauko, H.; van Helvoort, A.T.J.; Lee, S.; Fimland, B.-O.; Weman, H. Rectifying Single GaAsSb Nanowire Devices Based on Self-Induced Compositional Gradients. Nano Lett. 2015, 15, 3709-3715. [CrossRef] [PubMed]

13. Lemme, M.C.; Koppens, F.H.L.; Falk, A.L.; Rudner, M.S.; Park, H.; Levitov, L.S.; Marcus, C.M. Gate-Activated Photoresponse in a Graphene p-n Junction. Nano Lett. 2011, 11, 4134-4137. [CrossRef] [PubMed]

14. Kim, C.O.; Kim, S.; Shin, D.H.; Kang, S.S.; Kim, J.M.; Jang, C.W.; Joo, S.S.; Lee, J.S.; Kim, J.H.; Choi, S.-H.; et al. High photoresponsivity in an all-graphene $p-n$ vertical junction photodetector. Nat. Commun. 2014, 5, 3249. [CrossRef] [PubMed]

15. Nikitskiy, I.; Goossens, S.; Kufer, D.; Lasanta, T.; Navickaite, G.; Koppens, F.H.L.; Konstantatos, G. Integrating an electrically active colloidal quantum dot photodiode with a graphene phototransistor. Nat. Commun. 2016, 7, 11954. [CrossRef] [PubMed]

16. Bandara, S.V.; Gunapala, S.D.; Liu, J.K.; Rafol, S.B.; Hill, C.J.; Ting, D.Z.-Y.; Mumolo, J.M.; Trinh, T.Q.; Fastenau, J.M.; Liu, A.W.K. Tuning and tailoring of broadband quantum-well infrared photodetector responsivity spectrum. Appl. Phys. Lett. 2005, 86, 151104. [CrossRef]

17. Zhang, E.; Wang, P.; Li, Z.; Wang, H.; Song, C.; Huang, C.; Chen, Z.-G.; Yang, L.; Zhang, K.; Lu, S.; et al.

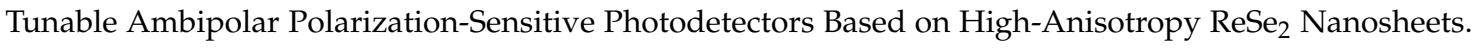
ACS Nano 2016, 10, 8067-8077. [CrossRef] [PubMed]

18. Singh, A.; Li, X.; Protasenko, V.; Galantai, G.; Kuno, M.; Xing, H.; Jena, D. Polarization-Sensitive Nanowire Photodetectors Based on Solution-Synthesized CdSe Quantum-Wire Solids. Nano Lett. 2007, 7, 2999-3006. [CrossRef] [PubMed]

19. Yuan, H.; Liu, X.; Afshinmanesh, F.; Li, W.; Xu, G.; Sun, J.; Lian, B.; Curto, A.G.; Ye, G.; Hikita, Y.; et al. Polarization-sensitive broadband photodetector using a black phosphorus vertical $p-n$ junction. Nat. Nanotechnol. 2015, 10, 707-713. [CrossRef] [PubMed]

20. Lhuillier, E.; Scarafagio, M.; Hease, P.; Nadal, B.; Aubin, H.; Xu, X.Z.; Lequeux, N.; Patriarche, G.; Ithurria, S.; Dubertret, B. Infrared Photodetection Based on Colloidal Quantum-Dot Films with High Mobility and Optical Absorption up to THz. Nano Lett. 2016, 16, 1282-1286. [CrossRef] [PubMed]

21. Lee, S.J.; Ku, Z.; Barve, A.; Montoya, J.; Jang, W.-Y.; Brueck, S.R.J.; Sundaram, M.; Reisinger, A.; Krishna, S.; Noh, S.K. A monolithically integrated plasmonic infrared quantum dot camera. Nat. Commun. 2011, 2, 286. [CrossRef] [PubMed]

22. Wu, W.; Bonakdar, A.; Mohseni, H. Plasmonic enhanced quantum well infrared photodetector with high detectivity. Appl. Phys. Lett. 2010, 96, 161107. [CrossRef]

23. Shishodia, M.S.; Unil Perera, A.G. Heterojunction plasmonic midinfrared detectors. J. Appl. Phys. 2011, $109,043108$. [CrossRef]

24. Shenoi, R.V.; Rosenberg, J.; Vandervelde, T.E.; Painter, O.J.; Krishna, S. Multispectral Quantum Dots-in-a-Well Infrared Detectors Using Plasmon Assisted Cavities. IEEE J. Quantum Electron. 2010, 46, 1051-1057. [CrossRef]

25. Fang, Z.; Liu, Z.; Wang, Y.; Ajayan, P.M.; Nordlander, P.; Halas, N.J. Graphene-Antenna Sandwich Photodetector. Nano Lett. 2012, 12, 3808-3813. [CrossRef] [PubMed]

26. Crouch, C.H.; Carey, J.E.; Shen, M.; Mazur, E.; Genin, F.Y. Infrared absorption by sulfur-doped silicon formed by femtosecond laser irradiation. Appl. Phys. A 2004, 79, 1635-1641. [CrossRef]

27. Zhong, H.; Guo, A.; Guo, G.; Li, W.; Jiang, Y. The Enhanced Light Absorptance and Device Application of Nanostructured Black Silicon Fabricated by Metal-assisted Chemical Etching. Nanoscale Res. Lett. 2016, 11, 322. [CrossRef] [PubMed]

28. Ariyawansa, G.; Perera, A.G.U.; Su, X.H.; Chakrabarti, S.; Bhattacharya, P. Multi-color tunneling quantum dot infrared photodetectors operating at room temperature. Infrared Phys. Technol. 2007, 50, 156-161. [CrossRef]

29. Tian, Z.-B.; Schuler-Sandy, T.; Krishna, S. Electron barrier study of mid-wave infrared interband cascade photodetectors. Appl. Phys. Lett. 2013, 103, 083501. [CrossRef] 
30. Gendron, L.; Koeniguer, C.; Berger, V.; Marcadet, X. High resistance narrow band quantum cascade photodetectors. Appl. Phys. Lett. 2005, 86, 121116. [CrossRef]

31. Chakrabarti, S.; Adhikary, S.; Halder, N.; Aytac, Y.; Perera, A.G.U. High-performance, long-wave $(\sim 10.2 \mu \mathrm{m})$ InGaAs/GaAs quantum dot infrared photodetector with quaternary In $0.21 \mathrm{Al} 0.21 \mathrm{Ga} 0.58$ As capping. Appl. Phys. Lett. 2011, 99, 181102. [CrossRef]

32. Goubet, N.; Jagtap, A.; Livache, C.; Martinez, B.; Portalès, H.; Xu, X.Z.; Lobo, R.P.S.M.; Dubertret, B.; Lhuillier, E. Terahertz HgTe Nanocrystals: Beyond Confinement. J. Am. Chem. Soc. 2018, 140, 5033-5036. [CrossRef] [PubMed]

33. Chen, M.; Lu, H.; Abdelazim, N.M.; Zhu, Y.; Wang, Z.; Ren, W.; Kershaw, S.V.; Rogach, A.L.; Zhao, N. Mercury Telluride Quantum Dot Based Phototransistor Enabling High-Sensitivity Room-Temperature Photodetection at $2000 \mathrm{~nm}$. ACS Nano 2017, 11, 5614-5622. [CrossRef] [PubMed]

34. Tang, X.; Wu, G.F.; Lai, K.W.C. Plasmon resonance enhanced colloidal HgSe quantum dot filterless narrowband photodetectors for mid-wave infrared. J. Mater. Chem. C. 2017, 5, 362-369. [CrossRef]

35. Konstantatos, G.; Howard, I.; Fischer, A.; Hoogland, S.; Clifford, J.; Klem, E.; Levina, L.; Sargent, E.H. Ultrasensitive solution-cast quantum dot photodetectors. Nature 2006, 442, 180-183. [CrossRef] [PubMed]

36. Zheng, D.; Wang, J.; Hu, W.; Liao, L.; Fang, H.; Guo, N.; Wang, P.; Gong, F.; Wang, X.; Fan, Z.; et al. When Nanowires Meet Ultrahigh Ferroelectric Field-High-Performance Full-Depleted Nanowire Photodetectors. Nano Lett. 2016, 16, 2548-2555. [CrossRef] [PubMed]

37. Miao, J.; Hu, W.; Guo, N.; Lu, Z.; Zou, X.; Liao, L.; Shi, S.; Chen, P.; Fan, Z.; Ho, J.C.; et al. Single InAs Nanowire Room-Temperature Near-Infrared Photodetectors. ACS Nano 2014, 8, 3628-3635. [CrossRef] [PubMed]

38. Fang, H.; Hu, W.; Wang, P.; Guo, N.; Luo, W.; Zheng, D.; Gong, F.; Luo, M.; Tian, H.; Zhang, X.; et al. Visible Light-Assisted High-Performance Mid-Infrared Photodetectors Based on Single InAs Nanowire. Nano Lett. 2016, 16, 6416-6424. [CrossRef] [PubMed]

39. Sun, Z.; Liu, Z.; Li, J.; Tai, G.; Lau, S.-P.; Yan, F. Infrared Photodetectors Based on CVD-Grown Graphene and $\mathrm{PbS}$ Quantum Dots with Ultrahigh Responsivity. Adv. Mater. 2012, 24, 5878-5883. [CrossRef] [PubMed]

40. Ni, Z.; Ma, L.; Du, S.; Xu, Y.; Yuan, M.; Fang, H.; Wang, Z.; Xu, M.; Li, D.; Yang, J.; et al. Plasmonic Silicon Quantum Dots Enabled High-Sensitivity Ultrabroadband Photodetection of Graphene-Based Hybrid Phototransistors. ACS Nano 2017, 11, 9854-9862. [CrossRef] [PubMed]

41. Cao, F.; Liao, Q.; Deng, K.; Chen, L.; Li, L.; Zhang, Y. Novel perovskite/ $\mathrm{TiO}_{2} / \mathrm{Si}$ trilayer heterojunctions for high-performance self-powered ultraviolet-visible-near infrared (UV-Vis-NIR) photodetectors. Nano Res. 2018, 11, 1722-1730. [CrossRef]

42. Tsao, S.; Lim, H.; Seo, H.; Zhang, W.; Razeghi, M. InP-Based Quantum-Dot Infrared Photodetectors With High Quantum Efficiency and High-Temperature Imaging. IEEE Sens. J. 2008, 8, 936-941. [CrossRef]

43. Durmaz, H.; Sookchoo, P.; Cui, X.; Jacobson, R.; Savage, D.E.; Lagally, M.G.; Paiella, R. SiGe Nanomembrane Quantum-Well Infrared Photodetectors. ACS Photonics 2016, 3, 1978-1985. [CrossRef]

44. Rogalski, A. Infrared detectors: Status and trends. Prog. Quantum Electron. 2003, 27, 59-210. [CrossRef]

45. Pan, J.L.; Fonstad, C.G. Theory, fabrication and characterization of quantum well infrared photodetectors. Mater. Sci. Eng. 2000, 28, 65-147. [CrossRef]

46. Sakata, H. Optimally designed layer formation for wavelength-selective photodetectors based on grating-assisted coupling. Opt. Quantum Electron. 1996, 28, 1129-1138. [CrossRef]

47. Le, D.T.; Morath, C.P.; Norton, H.E.; Cardimona, D.A.; Raghavan, S.; Rotella, P.; Stintz, S.A.; Fuchs, B.; Krishna, S. High responsivity, LWIR dots-in-a-well quantum dot infrared photodetectors. Infrared Phys. Technol. 2003, 44, 517-526. [CrossRef]

48. Wang, X.-J.; Zhai, S.-Q.; Zhuo, N.; Liu, J.-Q.; Liu, F.-Q.; Liu, S.-M.; Wang, Z.-G. Quantum dot quantum cascade infrared photodetector. Appl. Phys. Lett. 2014, 104, 171108. [CrossRef]

49. Machhadani, H.; Kandaswamy, P.; Sakr, S.; Vardi, A.; Wirtmüller, A.; Nevou, L.; Guillot, F.; Pozzovivo, G.; Tchernycheva, M.; Lupu, A.; et al. GaN/AlGaN intersubband optoelectronic devices. New J. Phys. 2009, 11, 125023. [CrossRef]

50. Krishna, S.; Gunapala, S.D.; Bandara, S.V.; Hill, C.; Ting, D.Z. Quantum Dot Based Infrared Focal Plane Arrays. Proc. IEEE 2007, 95, 1838-1852. [CrossRef]

51. Nevou, L.; Liverini, V.; Castellano, F.; Bismuto, A.; Faist, J. Asymmetric heterostructure for photovoltaic InAs quantum dot infrared photodetector. Appl. Phys. Lett. 2010, 97, 023505. [CrossRef] 
52. Maimon, S.; Wicks, G.W. $n B n$ detector, an infrared detector with reduced dark current and higher operating temperature. Appl. Phys. Lett. 2006, 89, 151109. [CrossRef]

53. Giorgetta, F.R.; Baumann, E.; Graf, M.; Ajili, L.; Hoyler, N.; Giovannini, M.; Faist, J.; Hofstetter, D.; Krötz, P.; Sonnabend, G. 16.5 $\mu \mathrm{m}$ quantum cascade detector using miniband transport. Appl. Phys. Lett. 2007, 90, 231111. [CrossRef]

54. Hofstetter, D.; Beck, M.; Faist, J. Quantum-cascade-laser structures as photodetectors. Appl. Phys. Lett. 2002, 81, 2683-2685. [CrossRef]

55. Barve, A.V.; Krishna, S. Photovoltaic quantum dot quantum cascade infrared photodetector. Appl. Phys. Lett. 2012, 100, 021105. [CrossRef]

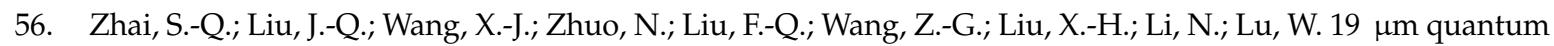
cascade infrared photodetectors. Appl. Phys. Lett. 2013, 102, 191120. [CrossRef]

57. McDonald, S.A.; Konstantatos, G.; Zhang, S.; Cyr, P.W.; Klem, E.J.D.; Levina, L.; Sargent, E.H. Solution-processed $\mathrm{PbS}$ quantum dot infrared photodetectors and photovoltaics. Nat. Mater. 2005, 4, 138-142. [CrossRef] [PubMed]

58. Lhuillier, E.; Keuleyan, S.; Guyot-Sionnest, P. Optical properties of HgTe colloidal quantum dots. Nanotechnology 2012, 23, 175705. [CrossRef] [PubMed]

59. He, J.; Qiao, K.; Gao, L.; Song, H.; Hu, L.; Jiang, S.; Zhong, J.; Tang, J. Synergetic Effect of Silver Nanocrystals Applied in PbS Colloidal Quantum Dots for High-Performance Infrared Photodetectors. ACS Photonics 2014, 1, 936-943. [CrossRef]

60. Zhang, H.; Zhang, Y.; Song, X.; Yu, Y.; Cao, M.; Che, Y.; Wang, J.; Yang, J.; Dai, H.; Zhang, G.; et al. High performance PbSe colloidal quantum dot vertical field effect phototransistors. Nanotechnology 2016, 27, 425204. [CrossRef] [PubMed]

61. Sarasqueta, G.; Choudhury, K.R.; So, F. Effect of Solvent Treatment on Solution-Processed Colloidal PbSe Nanocrystal Infrared Photodetectors. Chem. Mater. 2010, 22, 3496-3501. [CrossRef]

62. Park, M.; Choi, D.; Choi, Y.; Shin, H.; Jeong, K.S. Mid-Infrared Intraband Transition of Metal Excess Colloidal $\mathrm{Ag}_{2}$ Se Nanocrystals. ACS Photonics 2018, 5, 1907-1911. [CrossRef]

63. Livache, C.; Goubet, N.; Martinez, B.; Izquierdo, E.; Greboval, C.; Ithurria, S.; Lhuillier, E. HgTe, the Most Tunable Colloidal Material: From the Strong Confinement Regime to THz Material. MRS Adv. 2018, 3, $2913-2921$. [CrossRef]

64. Tang, X.; Lai, K.W.C. Detection of mid-infrared by HgTe colloidal quantum dots at room temperature. In Proceedings of the 2016 IEEE 16th International Conference on Nanotechnology (IEEE-NANO), Sendai, Japan, 22-25 August 2016; pp. 494-497.

65. Cheng, C.; Li, J.; Cheng, X. Photoluminescence lifetime and absorption spectrum of PbS nanocrystal quantum dots. J. Lumin. 2017, 188, 252-257. [CrossRef]

66. Moreels, I.; Lambert, K.; Smeets, D.; De Muynck, D.; Nollet, T.; Martins, J.C.; Vanhaecke, F.; Vantomme, A.; Delerue, C.; Allan, G.; et al. Size-Dependent Optical Properties of Colloidal PbS Quantum Dots. ACS Nano 2009, 3, 3023-3030. [CrossRef] [PubMed]

67. Inoshita, T.; Sakaki, H. Electron-phonon interaction and the so-called phonon bottleneck effect in semiconductor quantum dots. Phys. B Condens. Matter 1996, 227, 373-377. [CrossRef]

68. Tang, J.; Kemp, K.W.; Hoogland, S.; Jeong, K.S.; Liu, H.; Levina, L.; Furukawa, M.; Wang, X.; Debnath, R.; Cha, D.; et al. Colloidal-quantum-dot photovoltaics using atomic-ligand passivation. Nat. Mater. 2011, 10, 765-771. [CrossRef] [PubMed]

69. Clifford, J.P.; Konstantatos, G.; Johnston, K.W.; Hoogland, S.; Levina, L.; Sargent, E.H. Fast, sensitive and spectrally tuneable colloidal-quantum-dot photodetectors. Nat. Nanotechnol. 2009, 4, 40-44. [CrossRef] [PubMed]

70. Konstantatos, G.; Sargent, E.H. Colloidal quantum dot photodetectors. Infrared Phys. Technol. 2011, 54, $278-282$. [CrossRef]

71. Livache, C.; Goubet, N.; Martinez, B.; Jagtap, A.; Qu, J.; Ithurria, S.; Silly, M.G.; Dubertret, B.; Lhuillier, E. Band Edge Dynamics and Multiexciton Generation in Narrow Band Gap HgTe Nanocrystals. ACS Appl. Mater. Interfaces 2018, 10, 11880-11887. [CrossRef] [PubMed]

72. Al-Otaify, A.; Kershaw, S.V.; Gupta, S.; Rogach, A.L.; Allan, G.; Delerue, C.; Binks, D.J. Multiple exciton generation and ultrafast exciton dynamics in HgTe colloidal quantum dots. Phys. Chem. Chem. Phys. 2013, 15, 16864. [CrossRef] [PubMed] 
73. Goodwin, H.; Jellicoe, T.C.; Davis, N.J.L.K.; Böhm, M.L. Multiple exciton generation in quantum dot-based solar cells. Nanophotonics 2018, 7, 111-126. [CrossRef]

74. Mann, S.A.; Grote, R.R.; Osgood, R.M.; Alù, A.; Garnett, E.C. Opportunities and Limitations for Nanophotonic Structures To Exceed the Shockley-Queisser Limit. ACS Nano 2016, 10, 8620-8631. [CrossRef] [PubMed]

75. Keuleyan, S.E.; Guyot-Sionnest, P.; Delerue, C.; Allan, G. Mercury Telluride Colloidal Quantum Dots: Electronic Structure, Size-Dependent Spectra, and Photocurrent Detection up to $12 \mu \mathrm{m}$. ACS Nano 2014, 8, 8676-8682. [CrossRef] [PubMed]

76. Salihoglu, O.; Muti, A.; Kutluer, K.; Tansel, T.; Turan, R.; Ergun, Y.; Aydinli, A. “N” structure for type-II superlattice photodetectors. Appl. Phys. Lett. 2012, 101, 073505. [CrossRef]

77. Chen, M.; Shao, L.; Kershaw, S.V.; Yu, H.; Wang, J.; Rogach, A.L.; Zhao, N. Photocurrent Enhancement of HgTe Quantum Dot Photodiodes by Plasmonic Gold Nanorod Structures. ACS Nano 2014, 8, 8208-8216. [CrossRef] [PubMed]

78. Deng, Z.; Jeong, K.S.; Guyot-Sionnest, P. Colloidal Quantum Dots Intraband Photodetectors. ACS Nano 2014, 8, 11707-11714. [CrossRef] [PubMed]

79. Buurma, C.; Ciani, A.J.; Pimpinella, R.E.; Feldman, J.S.; Grein, C.H.; Guyot-Sionnest, P. Advances in HgTe Colloidal Quantum Dots for Infrared Detectors. J. Electron. Mater. 2017, 46, 6685-6688. [CrossRef]

80. Li, H.; Wang, X.; Xu, J.; Zhang, Q.; Bando, Y.; Golberg, D.; Ma, Y.; Zhai, T. One-Dimensional CdS Nanostructures: A Promising Candidate for Optoelectronics. Adv. Mater. 2013, 25, 3017-3037. [CrossRef] [PubMed]

81. Sudha, M.; Jagadish, C. III-V compound SC for optoelectronic devices. Mater. Today 2009, 12, $22-32$. [CrossRef]

82. LaPierre, R.R.; Robson, M.; Azizur-Rahman, K.M.; Kuyanov, P. A review of III-V nanowire infrared photodetectors and sensors. J. Phys. D Appl. Phys. 2017, 50, 123001. [CrossRef]

83. Alexander-Webber, J.A.; Groschner, C.K.; Sagade, A.A.; Tainter, G.; Gonzalez-Zalba, M.F.; Di Pietro, R.; Wong-Leung, J.; Tan, H.H.; Jagadish, C.; Hofmann, S.; et al. Engineering the Photoresponse of InAs Nanowires. ACS Appl. Mater. Interfaces 2017, 9, 43993-44000. [CrossRef] [PubMed]

84. Gu, F.; Zhang, L.; Yin, X.; Tong, L. Polymer Single-Nanowire Optical Sensors. Nano Lett. 2008, 8, $2757-2761$. [CrossRef] [PubMed]

85. Gu, F.; Yu, H.; Wang, P.; Yang, Z.; Tong, L. Light-Emitting Polymer Single Nanofibers via Waveguiding Excitation. ACS Nano 2010, 4, 5332-5338. [CrossRef] [PubMed]

86. Wade, A.; Lovera, P.; O'Carroll, D.; Doyle, H.; Redmond, G. Luminescent Optical Detection of Volatile Electron Deficient Compounds by Conjugated Polymer Nanofibers. Anal. Chem. 2015, 87, 4421-4428. [CrossRef] [PubMed]

87. Park, S.H.; Lim, T.W.; Yang, D.-Y.; Cho, N.C.; Lee, K.-S. Fabrication of a bunch of sub-30-nm nanofibers inside microchannels using photopolymerization via a long exposure technique. Appl. Phys. Lett. 2006, 89, 173133. [CrossRef]

88. Sun, Y.-L.; Dong, W.-F.; Niu, L.-G.; Jiang, T.; Liu, D.-X.; Zhang, L.; Wang, Y.-S.; Chen, Q.-D.; Kim, D.-P.; Sun, H.-B. Protein-based soft micro-optics fabricated by femtosecond laser direct writing. Light Sci. Appl. 2014, 3, e129. [CrossRef]

89. Juodkazis, S.; Mukai, N.; Wakaki, R.; Yamaguchi, A.; Matsuo, S.; Misawa, H. Reversible phase transitions in polymer gels induced by radiation forces. Nature 2000, 408, 178-181. [CrossRef] [PubMed]

90. Kawata, S.; Sun, H.-B.; Tanaka, T.; Takada, K. Finer features for functional microdevices. Nature 2001, 412, $697-698$. [CrossRef] [PubMed]

91. Wu, D.; Wu, S.-Z.; Niu, L.-G.; Chen, Q.-D.; Wang, R.; Song, J.-F.; Fang, H.-H.; Sun, H.-B. High numerical aperture microlens arrays of close packing. Appl. Phys. Lett. 2010, 97, 031109. [CrossRef]

92. Xiong, W.; Zhou, Y.S.; He, X.N.; Gao, Y.; Mahjouri-Samani, M.; Jiang, L.; Baldacchini, T.; Lu, Y.F. Simultaneous additive and subtractive three-dimensional nanofabrication using integrated two-photon polymerization and multiphoton ablation. Light Sci. Appl. 2012, 1, 2047-7538. [CrossRef]

93. Sun, Y.-L.; Sun, S.-M.; Wang, P.; Dong, W.-F.; Zhang, L.; Xu, B.-B.; Chen, Q.-D.; Tong, L.-M.; Sun, H.-B. Customization of Protein Single Nanowires for Optical Biosensing. Small 2015, 11, 2869-2876. [CrossRef] [PubMed] 
94. Sun, S.-M.; Sun, Y.-L.; Zheng, B.-Y.; Wang, P.; Hou, Z.-S.; Dong, W.-F.; Zhang, L.; Chen, Q.-D.; Tong, L.-M.; Sun, H.-B. Protein-based Y-junction optical micro-splitters with environment-stimulus-actuated adjustments. Sens. Actuators B Chem. 2016, 232, 571-576. [CrossRef]

95. Erhard, N.; Sarwar, A.T.M.G.; Yang, F.; McComb, D.W.; Myers, R.C.; Holleitner, A.W. Optical Control of Internal Electric Fields in Band Gap-Graded InGaN Nanowires. Nano Lett. 2015, 15, 332-338. [CrossRef] [PubMed]

96. Treu, J.; Bormann, M.; Schmeiduch, H.; Döblinger, M.; Morkötter, S.; Matich, S.; Wiecha, P.; Saller, K.; Mayer, B.; Bichler, M. Enhanced Luminescence Properties of InAs-InAsP Core-Shell Nanowires. Nano Lett. 2013, 13, 6070-6077. [CrossRef] [PubMed]

97. Alhodaib, A.; Noori, Y.J.; Carrington, P.J.; Sanchez, A.M.; Thompson, M.D.; Young, R.J.; Krier, A.; Marshall, A.R.J. Room-Temperature Mid-Infrared Emission from Faceted InAsSb Multi Quantum Wells Embedded in InAs Nanowires. Nano Lett. 2018, 18, 235-240. [CrossRef] [PubMed]

98. Li, L.; Pan, D.; Xue, Y.; Wang, X.; Lin, M.; Su, D.; Zhang, Q.; Yu, X.; So, H.; Wei, D.; et al. Near Full-Composition-Range High-Quality GaAs ${ }_{1-x} \mathrm{Sb}_{x}$ Nanowires Grown by Molecular-Beam Epitaxy. Nano Lett. 2017, 17, 622-630. [CrossRef] [PubMed]

99. Han, Y.; Zheng, X.; Fu, M.; Pan, D.; Li, X.; Guo, Y.; Zhao, J.; Chen, Q. Negative photoconductivity of InAs nanowires. Phys. Chem. Chem. Phys. 2016, 18, 818-826. [CrossRef] [PubMed]

100. Yang, Y.; Peng, X.; Kim, H.-S.; Kim, T.; Jeon, S.; Kang, H.K.; Choi, W.; Song, J.; Doh, Y.-J.; Yu, D. Hot Carrier Trapping Induced Negative Photoconductance in InAs Nanowires toward Novel Nonvolatile Memory. Nano Lett. 2015, 15, 5875-5882. [CrossRef] [PubMed]

101. Chen, L.; Schwarzer, D.; Lau, J.A.; Verma, V.B.; Stevens, M.J.; Marsili, F.; Mirin, R.P.; Nam, S.W.; Wodtke, A.M. Ultra-sensitive mid-infrared emission spectrometer with sub-ns temporal resolution. Opt. Express 2018, 26, 14859. [CrossRef] [PubMed]

102. Chen, L.; Schwarzer, D.; Verma, V.B.; Stevens, M.J.; Marsili, F.; Mirin, R.P.; Woo Nam, S.; Wodtke, A.M. Mid-infrared Laser-Induced Fluorescence with Nanosecond Time Resolution Using a Superconducting Nanowire Single-Photon Detector: New Technology for Molecular Science. Acc. Chem. Res. 2017, 50, 1400-1409. [CrossRef] [PubMed]

103. Arpaia, R.; Ejrnaes, M.; Parlato, L.; Tafuri, F.; Cristiano, R.; Golubev, D.; Sobolewski, R.; Bauch, T.; Lombardi, F.; Pepe, G.P. High-temperature superconducting nanowires for photon detection. Physica C 2015, 509, 16-21. [CrossRef]

104. Gol'tsman, G.N.; Okunev, O.; Chulkova, G.; Lipatov, A.; Semenov, A.; Smirnov, K.; Voronov, B.; Dzardanov, A.; Williams, C.; Sobolewski, R. Picosecond superconducting single-photon optical detector. Appl. Phys. Lett. 2001, 79, 705-707. [CrossRef]

105. Waks, E.; Inoue, K.; Oliver, W.D.; Diamanti, E.; Yamamoto, Y. High-efficiency photon-number detection for quantum information processing. IEEE J. Sel. Top. Quantum Electron. 2003, 9, 1502-1511. [CrossRef]

106. Bell, M.; Antipov, A.; Karasik, B.; Sergeev, A.; Mitin, V.; Verevkin, A. Photon Number-Resolved Detection With Sequentially Connected Nanowires. IEEE Trans. Appl. Supercond. 2007, 17, 289-292. [CrossRef]

107. Zheng, F.; Tao, X.; Yang, M.; Zhu, G.; Jin, B.; Kang, L.; Xu, W.; Chen, J.; Wu, P. Design of efficient superconducting nanowire single photon detectors with high polarization sensitivity for polarimetric imaging. J. Opt. Soc. Am. B 2016, 33, 2256-2264. [CrossRef]

108. Luszcz, K.; Bonvin, E.; Novotny, L. Optical near-field mapping with a superconducting nanowire detector. Appl. Phys. Lett. 2018, 113, 011103. [CrossRef]

109. Zheng, F.; Xu, R.; Zhu, G.; Jin, B.; Kang, L.; Xu, W.; Chen, J.; Wu, P. Design of a polarization-insensitive superconducting nanowire single photon detector with high detection efficiency. Sci. Rep. 2016, 6, 22710. [CrossRef] [PubMed]

110. Buckley, S.; Chiles, J.; McCaughan, A.N.; Moody, G.; Silverman, K.L.; Stevens, M.J.; Mirin, R.P.; Nam, S.W.; Shainline, J.M. All-silicon light-emitting diodes waveguide-integrated with superconducting single-photon detectors. Appl. Phys. Lett. 2017, 111, 141101. [CrossRef]

111. Mattioli, F.; Zhou, Z.; Gaggero, A.; Gaudio, R.; Jahanmirinejad, S.; Sahin, D.; Marsili, F.; Leoni, R.; Fiore, A. Photon-number-resolving superconducting nanowire detectors. Supercond. Sci. Technol. 2015, 28, 104001. [CrossRef]

112. Korneeva, Y.; Florya, I.; Semenov, I.; Korneev, I.; Goltsman, G. New Generation of Nanowire NbN Superconducting Single Photon Detector for Mid-Infrared. IEEE Trans. Appl. Supercond. 2011, 21, 323-326. [CrossRef] 
113. Heath, R.M.; Tanner, M.G.; Drysdale, T.D.; Miki, S.; Giannini, V.; Maier, S.A.; Hadfield, R.H. Nanoantenna Enhancement for Telecom-Wavelength Superconducting Single Photon Detectors. Nano Lett. 2015, 15, 819-822. [CrossRef] [PubMed]

114. Xia, F.; Wang, H.; Xiao, D.; Dubey, M.; Ramasubramaniam, A. Two-dimensional material nanophotonics. Nat. Photonics 2014, 8, 899-907. [CrossRef]

115. Zhou, X.; Zhang, Q.; Gan, L.; Li, H.; Xiong, J.; Zhai, T. Booming Development of Group IV-VI Semiconductors: Fresh Blood of 2D Family. Adv. Sci. 2016, 3, 1600177. [CrossRef] [PubMed]

116. Hafeez, M.; Gan, L.; Li, H.; Ma, Y.; Zhai, T. Large-Area Bilayer $\operatorname{ReS}_{2}$ Film/Multilayer ReS 2 Flakes Synthesized by Chemical Vapor Deposition for High Performance Photodetectors. Adv. Funct. Mater. 2016, 26, 4551-4560. [CrossRef]

117. Mak, K.F.; Shan, J. Photonics and optoelectronics of 2D semiconductor transition metal dichalcogenides. Nat. Photonics 2016, 10, 216-226. [CrossRef]

118. Rogers, J.A.; Someya, T.; Huang, Y. Materials and mechanics for stretchable electronics. Science 2010, 327, $1603-1607$. [CrossRef] [PubMed]

119. Liu, M.; Yin, X.; Ulin-Avila, E.; Geng, B.; Zentgraf, T.; Ju, L.; Wang, F.; Zhang, X. A graphene-based broadband optical modulator. Nature 2011, 474, 64-67. [CrossRef] [PubMed]

120. Rodin, A.S.; Carvalho, A.; Castro Neto, A.H. Strain-Induced Gap Modification in Black Phosphorus. Phys. Rev. Lett. 2014, 112, 176801. [CrossRef] [PubMed]

121. Lee, Y.-H.; Yu, L.; Wang, H.; Fang, W.; Ling, X.; Shi, Y.; Lin, C.-T.; Huang, J.-K.; Chang, M.-T.; Chang, C.-S.; et al. Synthesis and Transfer of Single-Layer Transition Metal Disulfides on Diverse Surfaces. Nano Lett. 2013, 13, 1852-1857. [CrossRef] [PubMed]

122. Li, H.; Wu, J.; Huang, X.; Yin, Z.; Liu, J.; Zhang, H. A Universal, Rapid Method for Clean Transfer of Nanostructures onto Various Substrates. ACS Nano 2014, 8, 6563-6570. [CrossRef] [PubMed]

123. Anguita, J.V.; Ahmad, M.; Haq, S.; Allam, J.; Silva, S.R.P. Ultra-broadband light trapping using nanotextured decoupled graphene multilayers. Sci. Adv. 2016, 2, e1501238. [CrossRef] [PubMed]

124. Fang, Z.; Wang, Y.; Schlather, A.E.; Liu, Z.; Ajayan, P.M.; García de Abajo, F.J; Nordlander, P.; Zhu, X.; Halas, N.J. Active Tunable Absorption Enhancement with Graphene Nanodisk Arrays. Nano Lett. 2014, 14, 299-304. [CrossRef] [PubMed]

125. Geim, A.K. Graphene: Status and prospects. Science 2009, 324, 1530-1534. [CrossRef] [PubMed]

126. Bolotin, K.I.; Sikes, K.J.; Jiang, Z.; Klima, M.; Fudenberg, G.; Hone, J.; Kim, P.; Stormer, H.L. Ultrahigh electron mobility in suspended graphene. Solid State Commun. 2008, 146, 351-355. [CrossRef]

127. George, P.A.; Strait, J.; Dawlaty, J.; Shivaraman, S.; Chandrashekhar, M.; Rana, F.; Spencer, M.G. Ultrafast Optical-Pump Terahertz-Probe Spectroscopy of the Carrier Relaxation and Recombination Dynamics in Epitaxial Graphene. Nano Lett. 2008, 8, 4248-4251. [CrossRef] [PubMed]

128. Fratini, S.; Guinea, F. Substrate-limited electron dynamics in graphene. Phys. Rev. B 2008, 77, 195415. [CrossRef]

129. Xia, F.; Mueller, T.; Lin, Y.; Valdes-Garcia, A.; Avouris, P. Ultrafast graphene photodetector. Nat. Nanotechnol. 2009, 4, 839-843. [CrossRef] [PubMed]

130. Xie, C.; Mak, C.; Tao, X.; Yan, F. Photodetectors Based on Two-Dimensional Layered Materials Beyond Graphene. Adv. Funct. Mater. 2017, 27, 1603886. [CrossRef]

131. Luo, L.-B.; Chen, J.-J.; Wang, M.-Z.; Hu, H.; Wu, C.-Y.; Li, Q.; Wang, L.; Huang, J.-A.; Liang, F.-X. Near-Infrared Light Photovoltaic Detector Based on GaAs Nanocone Array/Monolayer Graphene Schottky Junction. Adv. Funct. Mater. 2014, 24, 2794-2800. [CrossRef]

132. Schornbaum, J.; Winter, B.; Schießl, S.P.; Gannott, F.; Katsukis, G.; Guldi, D.M.; Spiecker, E.; Zaumseil, J. Epitaxial Growth of PbSe Quantum Dots on $\mathrm{MoS}_{2}$ Nanosheets and their Near-Infrared Photoresponse. Adv. Funct. Mater. 2014, 24, 5798-5806. [CrossRef]

133. Manga, K.K.; Wang, J.; Lin, M.; Zhang, J.; Nesladek, M.; Nalla, V.; Ji, W.; Loh, K.P. High-Performance Broadband Photodetector Using Solution-Processible PbSe-TiO2-Graphene Hybrids. Adv. Mater. 2012, 24, 1697-1702. [CrossRef] [PubMed]

134. Qiao, H.; Yuan, J.; Xu, Z.; Chen, C.; Lin, S.; Wang, Y.; Song, J.; Liu, Y.; Khan, Q.; Hoh, H.Y.; et al. Broadband Photodetectors Based on Graphene- $\mathrm{Bi}_{2} \mathrm{Te}_{3}$ Heterostructure. ACS Nano 2015, 9, 1886-1894. [CrossRef] [PubMed] 
135. Yu, S.H.; Lee, Y.; Jang, S.K.; Kang, J.; Jeon, J.; Lee, C.; Lee, J.Y.; Kim, H.; Hwang, E.; Lee, S.; et al. Dye-Sensitized $\mathrm{MoS}_{2}$ Photodetector with Enhanced Spectral Photoresponse. ACS Nano 2014, 8, 8285-8291. [CrossRef] [PubMed]

136. Robin, A.; Lhuillier, E.; Xu, X.Z.; Ithurria, S.; Aubin, H.; Ouerghi, A.; Dubertret, B. Engineering the Charge Transfer in all 2D Graphene-Nanoplatelets Heterostructure Photodetectors. Sci. Rep. 2016, 6, 24909. [CrossRef] [PubMed]

137. Zeng, L.-H.; Wang, M.-Z.; Hu, H.; Nie, B.; Yu, Y.-Q.; Wu, C.-Y.; Wang, L.; Hu, J.-G.; Xie, C.; Liang, F.-X.; et al. Monolayer Graphene/Germanium Schottky Junction As High-Performance Self-Driven Infrared Light Photodetector. Appl. Mater. Interfaces 2013, 5, 9362-9366. [CrossRef] [PubMed]

138. Huo, N.; Gupta, S.; Konstantatos, G. $\mathrm{MoS}_{2}-\mathrm{HgTe}$ Quantum Dot Hybrid Photodetectors beyond $2 \mu \mathrm{m}$. Adv. Mater. 2017, 29, 1606576. [CrossRef] [PubMed]

139. Venuthurumilli, P.K.; Ye, P.D.; Xu, X. Plasmonic Resonance Enhanced Polarization-Sensitive Photodetection by Black Phosphorus in Near Infrared. ACS Nano 2018, 12, 4861-4867. [CrossRef] [PubMed]

140. Li, W.; Valentine, J. Metamaterial Perfect Absorber Based Hot Electron Photodetection. Nano Lett. 2014, 14, 3510-3514. [CrossRef] [PubMed]

141. Maier, S.A.; Atwater, H.A. Plasmonics: Localization and guiding of electromagnetic energy in metal/dielectric structures. J. Appl. Phys. 2005, 98, 011101. [CrossRef]

142. Noguez, C. Surface Plasmons on Metal Nanoparticles: The Influence of Shape and Physical Environment. J. Phys. Chem. C. 2007, 111, 3806-3819. [CrossRef]

143. Liz-Marzán, L.M. Tailoring Surface Plasmons through the Morphology and Assembly of Metal Nanoparticles. Langmuir 2005, 22, 32-41. [CrossRef] [PubMed]

144. Yakimov, A.I.; Kirienko, V.V.; Bloshkin, A.A.; Armbrister, V.A.; Dvurechenskii, A.V. Plasmon polariton enhanced mid-infrared photodetectors based on Ge quantum dots in Si. J. Appl. Phys. 2017, 122, 13301. [CrossRef]

145. Ozbay, E. Plasmonics: Merging Photonics and Electronics at Nanoscale Dimensions. Science 2006, 311, $189-193$. [CrossRef] [PubMed]

146. Hutter, E.; Fendler, J.H. Exploitation of Localized Surface Plasmon Resonance. Adv. Mater. 2004, 16, $1685-1706$. [CrossRef]

147. Wang, W.; Klots, A.; Prasai, D.; Yang, Y.; Bolotin, K.I.; Valentine, J. Hot Electron-Based Near-Infrared Photodetection Using Bilayer $\mathrm{MoS}_{2}$. Nano Lett. 2015, 15, 7440-7444. [CrossRef] [PubMed]

148. Barnes, W.L.; Dereux, A.; Ebbesen, T.W. Surface plasmon subwavelength optics. Nature 2003, 424, 824-830. [CrossRef] [PubMed]

149. Zhu, Z.; Zou, Y.; Hu, W.; Li, Y.; Gu, Y.; Cao, B.; Guo, N.; Wang, L.; Song, J.; Zhang, S.; et al. Near-Infrared Plasmonic 2D Semimetals for Applications in Communication and Biology. Adv. Funct. Mater. 2016, 26, 1793-1802. [CrossRef]

150. Xi, M.; Rn, B.; Reinhard, M. Localized Surface Plasmon Coupling between Mid-IR-Resonant ITO Nanocrystals. J. Phys. Chem. C 2018, 122, 5698-5704. [CrossRef] [PubMed]

151. Echtermeyer, T.J.; Milana, S.; Sassi, U.; Eiden, A.; Wu, M.; Lidorikis, E.; Ferrari, A.C. Surface Plasmon Polariton Graphene Photodetectors. Nano Lett. 2016, 16, 8-20. [CrossRef] [PubMed]

152. Chang, C.-C.; Sharma, Y.D.; Kim, Y.-S.; Bur, J.A.; Shenoi, R.V.; Krishna, S.; Huang, D.; Lin, S.-Y. A Surface Plasmon Enhanced Infrared Photodetector Based on InAs Quantum Dots. Nano Lett. 2010, 10, 1704-1709. [CrossRef] [PubMed]

153. Yao, Y.; Shankar, R.; Rauter, P.; Song, Y.; Kong, J.; Loncar, M.; Capasso, F. High-Responsivity Mid-Infrared Graphene Detectors with Antenna-Enhanced Photocarrier Generation and Collection. Nano Lett. 2014, 14, 3749-3754. [CrossRef] [PubMed]

154. Wu, D.; Yan, K.; Zhou, Y.; Wang, H.; Lin, L.; Peng, H.; Liu, Z. Plasmon-Enhanced Photothermoelectric Conversion in Chemical Vapor Deposited Graphene p-n Junctions. J. Am. Chem. Soc. 2013, 135, 10926-10929. [CrossRef] [PubMed]

155. Lin, K.-T.; Chen, H.-L.; Lai, Y.-S.; Yu, C.-C. Silicon-based broadband antenna for high responsivity and polarization-insensitive photodetection at telecommunication wavelengths. Nat. Commun. 2014, 5, 3288. [CrossRef] [PubMed]

156. Ho, Y.-L.; Huang, L.-C.; Delaunay, J.-J. Spectrally Selective Photocapacitance Modulation in Plasmonic Nanochannels for Infrared Imaging. Nano Lett. 2016, 16, 3094-3100. [CrossRef] [PubMed] 
157. Liu, C.-H.; Chang, Y.-C.; Norris, T.B.; Zhong, Z. Graphene photodetectors with ultra-broadband and high responsivity at room temperature. Nat. Nanotechnol. 2014, 9, 273-278. [CrossRef] [PubMed]

158. Guo, Q.; Pospischil, A.; Bhuiyan, M.; Jiang, H.; Tian, H.; Farmer, D.; Deng, B.; Li, C.; Han, S.-J.; Wang, H.; et al. Black Phosphorus Mid-Infrared Photodetectors with High Gain. Nano Lett. 2016, 16, 4648-4655. [CrossRef] [PubMed]

159. Huang, L.; Tan, W.C.; Wang, L.; Dong, B.; Lee, C.; Ang, K.-W. Infrared Black Phosphorus Phototransistor with Tunable Responsivity and Low Noise Equivalent Power. ACS Appl. Mater. Interfaces 2017, 9, 36130-36136. [CrossRef] [PubMed]

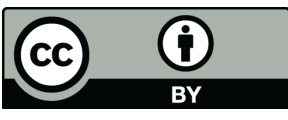

(C) 2018 by the authors. Licensee MDPI, Basel, Switzerland. This article is an open access article distributed under the terms and conditions of the Creative Commons Attribution (CC BY) license (http:/ / creativecommons.org/licenses/by/4.0/). 